\title{
Hypoxia-induced alternative splicing: the 11th Hallmark of Cancer
}

\author{
Antonietta Rosella Farina, Lucia Cappabianca, Michela Sebastiano, Veronica Zelli, Stefano Guadagni and \\ Andrew Reay Mackay ${ }^{*}$ (D)
}

\begin{abstract}
Hypoxia-induced alternative splicing is a potent driving force in tumour pathogenesis and progression. In this review, we update currents concepts of hypoxia-induced alternative splicing and how it influences tumour biology. Following brief descriptions of tumour-associated hypoxia and the pre-mRNA splicing process, we review the many ways hypoxia regulates alternative splicing and how hypoxia-induced alternative splicing impacts each individual hallmark of cancer. Hypoxia-induced alternative splicing integrates chemical and cellular tumour

microenvironments, underpins continuous adaptation of the tumour cellular microenvironment responsible for metastatic progression and plays clear roles in oncogene activation and autonomous tumour growth, tumor suppressor inactivation, tumour cell immortalization, angiogenesis, tumour cell evasion of programmed cell death and the anti-tumour immune response, a tumour-promoting inflammatory response, adaptive metabolic reprogramming, epithelial to mesenchymal transition, invasion and genetic instability, all of which combine to promote metastatic disease. The impressive number of hypoxia-induced alternative spliced protein isoforms that characterize tumour progression, classifies hypoxia-induced alternative splicing as the 11th hallmark of cancer, and offers a fertile source of potential diagnostic/prognostic markers and therapeutic targets.
\end{abstract}

Keywords: Hypoxia, Alternative splicing, Cancer hallmarks

\section{Background}

Tumour chemical and cellular microenvironments interact continually to select survival-adapted tumour cell and tumour-associated normal cell populations, and underpins both metastatic progression and therapeutic resistance. The tumour cellular microenvironment is comprised of "normal" (vascular, stromal and inflammatory cells) and neoplastic components that co-exist within a poorly defined and poorly organized extracellular matrix, characterized by heterogeneous niches created by a highly abnormal vasculature and episodes of microenvironmental hypoxic, nutrient, metabolic and redox stress, which elicit cellular hypoxic, nutrient, oxidative and metabolic stress responses. Tumour hypoxia

\footnotetext{
* Correspondence: andrewreay.mackay@univaq.it

Department of Applied Clinical and Biotechnological Sciences, University of L'Aquila, 67100 L'Aquila, Italy
}

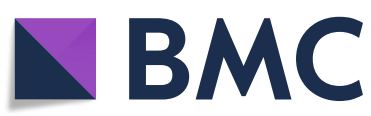

(c) The Author(s). 2020 Open Access This article is licensed under a Creative Commons Attribution 4.0 International License, which permits use, sharing, adaptation, distribution and reproduction in any medium or format, as long as you give appropriate credit to the original author(s) and the source, provide a link to the Creative Commons licence, and indicate if changes were made. The images or other third party material in this article are included in the article's Creative Commons licence, unless indicated otherwise in a credit line to the material. If material is not included in the article's Creative Commons licence and your intended use is not permitted by statutory regulation or exceeds the permitted use, you will need to obtain permission directly from the copyright holder. To view a copy of this licence, visit http://creativecommons.org/licenses/by/4.0/. The Creative Commons Public Domain Dedication waiver (http://creativecommons.org/publicdomain/zero/1.0/) applies to the data made available in this article, unless otherwise stated in a credit line to the data. lular components, combined with oncogene-promoted metabolic changes, result in the malignant tumourassociated "Warburg" metabo-type [1-3]. The metabotype, furthermore, promotes an acidic reducing tumour microenvironment, which together with tumour hypoxia, acts as potent driving forces for survival adaptation $[4$, 5], selecting "normal" and neoplastic tumour cellular components that exhibit increased resistance to programmed cell-death, a pro-angiogenic phenotype, sustained metabolic glycolytic reprogramming, progressive epithelial/mesenchymal (EMT) and stem cell-like dedifferentiation, enhanced motile, invasive, scattering and metastatic behaviour, increased genetic instability and enhanced therapeutic resistance [5-13]. 


\section{Tumour hypoxia}

Tumour-hypoxia results when tumour cellular components are deprived of oxygen and occurs during all phases of tumour progression, from early initiation through clonal expansion to metastatic progression [14]. Solid tumours are characterized by heterogenous hypoxic areas adjacent to near normoxic regions and exhibit $\left[\mathrm{pO}_{2}\right]$ concentrations $\leq 2.5 \mathrm{mmHg}$, significantly below those of normal vascular tissues, as a result of an imbalance between oxygen consumption and supply, e.g. $\left[\mathrm{pO}_{2}\right]$ of $10-16 \mathrm{mmHg}$ in cervical tumour tissues is significantly lower than the $\left[\mathrm{pO}_{2}\right] 40-42 \mathrm{mmHg}$ of normal cervical tissues $[9,10,15]$.

Tumour hypoxia arises from a variety of mechanisms. Tumour perfusion-hypoxia is caused by an abnormal disorganized tumour vasculature, characterized by structural, functional and cellular abnormalities and inadequate blood flow, resulting in transient ischemic episodes of varying duration caused by blockage and/or flow stasis. Tumour diffusion-hypoxia is caused by $\mathrm{O}_{2}$ diffusion distances $>70 \mu \mathrm{m}$ between tumour tissues and blood vessels, and blood flow countercurrents within the tumour microvascular. Tumour anemic hypoxia is caused by reduced $\mathrm{O}_{2}$ transport capacity resulting from the tumour itself or by systemic anemia caused by chemotherapy (Fig. 1a). In general, tumour-hypoxia is independent of tumour size, stage, histopathological type and grade, and also independent of patient age, parity, menopausal status and smoking habits $[6,7,16]$.

\section{Pre-mRNA splicing and alternative splicing}

Pre-mRNA splicing represents the process whereby noncoding intronic sequences within a gene are coordinately excised from pre-mRNA transcripts, and coding exons are ligated together to form a single mature protein encoding mRNA molecule. This maturation process occurs within nuclear speckles, which are sites of active transcription. Alternative splicing represents the exclusion or inclusion of different exons and/or intron sequences within the mature mRNA sequence [16, 17]. As genes numbers stopped increasing during evolution, alternative splicing became the main source of protein complexity, and functional diversity. The current alternative splice record is held by the Drosophila DISCAM gene, which is expressed as 38,000 individual splice variants, which represent more than the entire number of Drosophila genes [18]. In humans, alternative splicing accounts for $\approx 100$, 000 different proteins, is largely responsible for proteomic complexity that cannot be explained by gene numbers alone and is tightly regulated in order to provide sufficient adaptive flexibility to gene expression, whilst limiting the potential for chaos $[19,20]$.

Splicing initiates with spliceosome recruitment to the $5^{\prime}$ exon-intron splice junction and subsequent phosphodiester bond cleavage at the $5^{\prime}$ splice site, in a process involving a branch point adenosine and formation of an intermediate lariat structure, subsequently liberated by phosphodiester bond cleavage at the 3' splice site exon-intron junction, which also depends upon a free 5' exon hydroxyl group. Following intron splicing, exons are ligated together to form an in-frame mature protein encoding mRNA sequence (Fig. 1b). Alternative splicing is regulated by many factors, including enhancer and/or silencer cis-elements located within exons and/or introns that bind heterogeneous RNA binding (hnRNPs) or serine-arginine-rich (SR) trans-acting proteins, relative splice-site strengths, the localization of splice enhancing and/or silencing cis-elements, pre-mRNA secondary structure, the transcriptional elongation rate, the lengths of exons and introns, and the presence of modified RNA nucleotides (Fig. 1c and d) [21-25].

The $5^{\prime}$ splice site is composed of 9 nucleotides, demarcates the exon-intron boundary and recruits U1 snRNP. The 3' splice site contains an AG dinucleotide that delineates the exon-intron boundary and contains an upstream polypyrimidine tract, responsible for recruiting U2AF heterodimers, the U2AF65 component of which binds the pyrimidine tract and the U2AF35 subunit binds the AG dinucleotide, facilitating U2 snRNP recruitment to the intronic branch point. Alterations in these interactions regulate alternative splicing and result in either exon cassette inclusion or skipping, intron retention, mutually exclusive exon use, alternative first and last exon use, alternative $5^{\prime}$ and $3^{\prime}$ splice site use or the selection of alternative $5^{\prime}$ and $3^{\prime}$ untranslated regions (UTRs). Splice site strength is calculated by maximum entropy principle and dictates spliceosome component recruitment and assembly. The $5^{\prime}$ and $3^{\prime}$ splice sites play equal roles in cassette exon inclusion and the sum of $5^{\prime}$ and $3^{\prime}$ splice site scores predicts exon inclusion. Pre-mRNA secondary structure also regulates alternative splicing, as spliceosome components and regulators bind single stranded RNA and can be masked by secondary structure. Splicing can also be influenced by protein interaction (e.g. hnRNPA1 promotes distal 5' spice site activation by looping out an internal exon), which results in $\approx 4 \%$ of alternative splicing events. Regulation of alternative splicing by cis-elements depends upon recruitment of trans-acting hnRNPs and SR splicing factors that are required for spliceosome assembly. Cis-element localization is critical for this process and may act either as an exon splice enhancer (ESE), exon splicing silencer (ESS), intron splicing enhancer (ISE) or intron splicing silencer (ISS). ESEs recruit SR proteins to exons and localize spliceosome components adjacent to the intron via protein-protein interactions, whereas ESSs recruit hnRNPs to pre-mRNAs to repress exon inclusion. In general, SR proteins bound to exons 

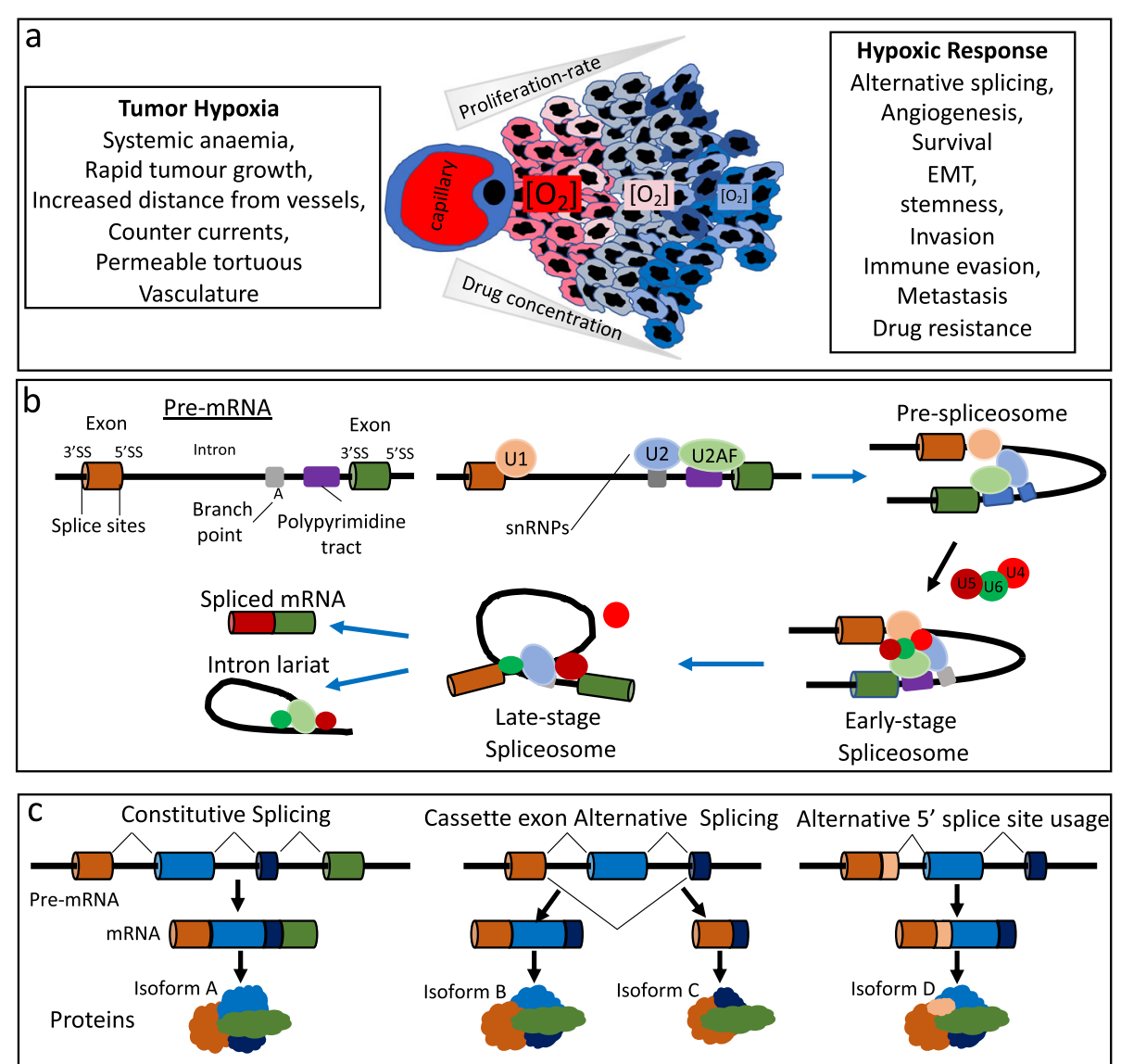

Alternative $3^{\prime}$ splice site usage
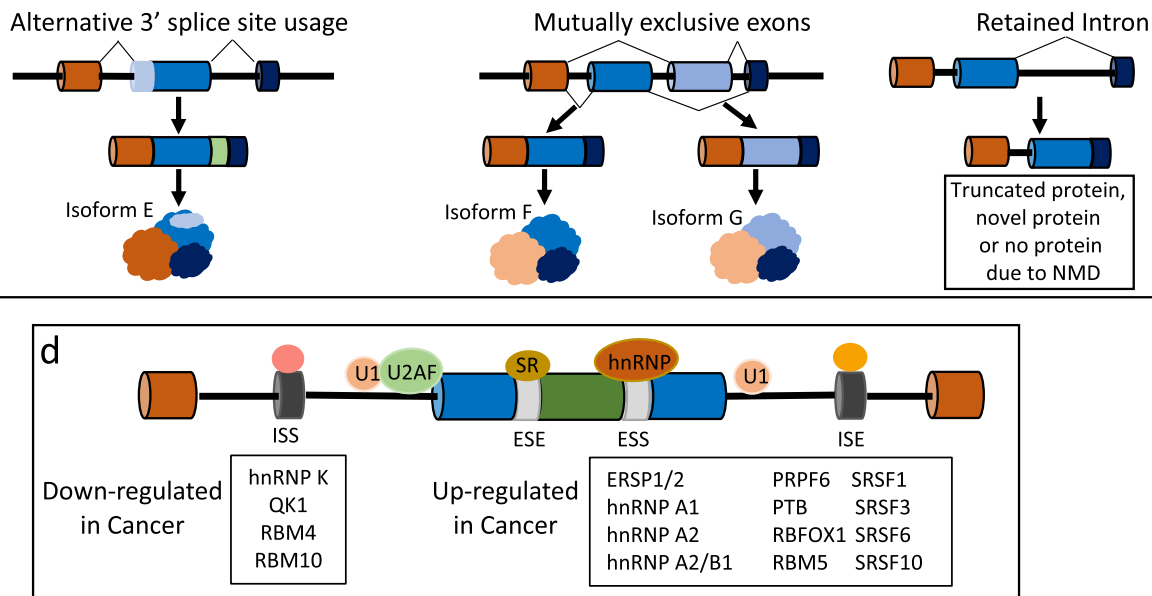

Fig. 1 Tumour hypoxia, constitutive and alternative Pre-mRNA splicing. Schematic representations of: a tumour hypoxia, the mechanisms involved in promoting the hypoxic tumour microenvironment and resulting cellular tumour promoting hypoxic response, including hypoxiainduced alternative splicing; $\mathbf{b}$ splice site, intron and exon architecture and interaction with splicing factors and spliceosome components that select splice sites and eliminate intron sequences via the formation of a lariat structure, followed by the splicing together of exons; c constitutive pre-mRNA splicing and alternative splicing by cassette exons skipping, alternative $5^{\prime}$ splice site use, alternative $3^{\prime}$ splice site use, the use of mutually exclusive exons and by retaining introns; d ESE, ESS, ISE and ISS splice elements plus splicing factors down-regulated or up-regulated in cancer

upstream of the $5^{\prime}$ splice site activate splicing but repress splicing when bound to introns downstream of $5^{\prime}$ splice sites, with alternative splicing promoted by alterations in splice site trans-acting SR and hnRNP protein expression. RNA polymerase II elongation rates, which are regulated by hypoxia, also regulate alternative splicing, with faster rates facilitate exon skipping, and slower rates facilitating sub-optimal splice-site recognition and 
RNA secondary structure formation (e.g. in fibronectin ED1 exon inclusion or exclusion) [26, 27]. With respect to exon and intron size, large exons ( $>500$ nucleotides) flanked by large introns (>500 nucleotides) are more likely to be skipped and recognized when flanked by short exons (<500 nucleotides). In contrast, short exons $(<500$ nucleotides) are recognized when flanked by large introns ( $>500$ nucleotides) $[28,29]$.

Post-transcriptionally modified nucleotides in premRNAs and snRNAs also influence spliceosome recruitment and promote alternative splicing. 2'-O-methyl, pseudo-uridine and trimethylated guanosine cap (m3G) modifications in U2 SnRNAs are critical for splicing reactions and nuclear U-snRNP importation, posttranscriptional $\mathrm{m} 6 \mathrm{~A}$ modifications in pre-mRNAs influence secondary structure, altering single-strand RNAs and RNA binding motif accessibility, and adenosine deaminase conversion of adenosine to inosine creates novel splice sites by converting AA dinucleotides to AI dinucleotides that promote alternative splicing [30]. Alternative splicing occurs in $\approx 86-88 \%$ of human genes. It is a highly complicated process that is tightly regulated under physiological conditions and responsible for the transcriptome diversity required for all aspects of physiological cell behaviour (Fig. 1b, c and d).

\section{Hypoxia-induced gene expression and alternative splicing}

The response to hypoxia includes a series of adaptation mechanisms that promote cell survival. At the systemic level, the carotid body within the carotid artery senses decreased $\mathrm{O}_{2}$ levels and stimulates breathing and cardiovascular output [31]. This response involves calcium and voltage activated $\mathrm{K}(\mathrm{BK})$ channels expressed in the carotid body and also by neuroepithelia, the $\alpha$ subunits of which are sensitive to alternative splicing, with hypoxia inducing inclusion of the stress-regulated exon STREX to confer sensitivity to hypoxia in a tissue specific pattern, providing a tissue-specific mechanism to control cellular responses to hypoxia [32]. Cellular molecular oxygenation sensing depends also upon oxygendependent oxygenases, comprised of a family of 2oxoglutarate-dependent oxygenase, including the hypoxia-inducible factor (HIF) oxygen-dependent prolylhydroxylase PHD [33]. Hypoxia inhibits PHD activity resulting in the accumulation, stabilization and activation of HIF transcription factors, that promote HIFtarget gene expression, alternative splicing of HIF-target and non-HIF target genes and also induce 4E-BP1 phosphorylation-dependent inhibition of capped nonHIF target gene mRNA translation, also inhibited by the hypoxia-induced RNA binding protein EVLAV1 (HuR) that regulates the expression of translation initiating factor 4E nuclear import factor 1 (Eif4enif1) [34-40].
Under normoxic conditions, proline hydroxylated HIF1 $\alpha$ is targeted for proteasomal degradation by the vonHippel Lindau tumour suppressor (pVHL), complexed with elongin $B$, elongin $C$, Cullin2 and Rbx1 (33). This mechanism is inactivated by hypoxia, resulting in HIF $\alpha$ dissociation and stabilization, nuclear translocation and formation of HIF $\alpha / \beta$ heterodimers, composed of one of three $\alpha$ subunits (HIF1 $\alpha$, HIF $2 \alpha$ and HIF3 $\alpha$ ) and one of two $\beta$ subunits (HIF- $\beta$ and ARNT2), leading to HIFbinding to hypoxia responsive elements (HREs) in gene promoters and transcription of an impressive number of HIF-target genes, involved in metabolic adaptation, angiogenesis, survival, cellular motility, staminality and metastatic progression [13, 41-44]. This response also involves alternative splicing of peptidyl prolyl isomerase-1 (Pin1), which binds and stabilizes HIF1 $\alpha$ [45], by repressing long non-coding (Lnc) RNA PIN1-v2 alternative splice variant that inhibits HIF $1 \alpha$ transcription, implicating the hypoxiaregulated alternative Pin1 splice equilibrium in hypoxiainduced, HIF-1-dependent gene expression [46]. Hypoxia also activates $\mathrm{p} 50 / \mathrm{p} 65 \mathrm{NF}-\mathrm{kB}$ transcription factor that is also negatively regulated by PHD-mediated proline hydroxylation [47], promotes CREB phosphorylationdependent transcription [48] and enhances NF-E2-related factor 2 (Nrf2) [49], STAT [50] and c-Myc transcriptional activity, confirming regulation of both HIF-target and non-HIF-target gene transcription.

Hypoxia-induced alternative splicing is critical for adaptation of both normal and tumour cellular microenvironments and is central to one of the most important functions of the normal and tumour hypoxic responses, angiogenesis, responsible for vascularizing hypoxic tissues [51]. The neovascularization of hypoxic tissues is achieved by lowering the ratio of angiogenesis inhibitors to angiogenesis promoters and depends upon hypoxiainduced, HIF-dependent, alternative splicing that promotes a pro-angiogenic VEGFA $\mathrm{A}_{165 a}$ alternative splice equilibrium, at the expense of the anti-angiogenic VEG$\mathrm{FA}_{165 \mathrm{~b}}$ isoform (see below). Hypoxia also regulates HIF$1 \alpha$ splicing during angiogenesis and promotes expression of the angiogenesis inhibitory alternatively spliced HIF$3 \alpha$ IPAS isoform, that binds HIF1 $\alpha$ but not HIF- $\beta$ to inhibit HIF-1-mediated transcription, up-regulates alternative HIF-3 44 splicing to suppresses HIF-dependent transcription and also induces the expression of a dominant negative exon 11 and 12 skipped HIF-1 $\alpha 516$ isoform, providing negative feedback loops that also regulate metabolism, confirming a high degree of complexity in hypoxia-regulated alternative splicing in angiogenesis $[52,53]$.

\section{Hypoxia-induced alternative splicing in cancer}

Hypoxia induces alternative splicing in normal and neoplastic tumour components. In human endothelial cells 
hypoxia been shown to induce 342 alternative splicing events [54], in liver cancer cells induces 3059 alternative splicing events in 2005 genes, contributing to dedifferentiation and genome instability [55], and in breast cancer cells $\approx 2000$ alternative splicing events, with estimated alternative splice rates of $\approx 1.78$ events per HIF-target gene and $\approx 1.53$ events per non-HIF-target gene, distributed relatively evenly between exon cassettes inclusion and exclusion reported in breast cancer, hepatocellular carcinoma, neuroblastoma and head and neck squamous carcinoma cells [56]. With respect to HIF-target genes, the majority of hypoxia-induced alternative splicing events involve genes that regulate oxy-reductase activity, glycolysis, glucose uptake, ATP-binding, protein kinase activity, pleckstrin homology, rho signaling, cytoskeletal organisation and cell death and, in general, favor expression of full length exon-included over exon-skipped isoforms, whereas hypoxia-induced exon-excluded isoforms are predominant in non-HIF target genes [36]. Deep sequencing in 16 different cancer types, including breast, colon, head and neck and lung cancers has also identified $>1000$ hypoxia-induced alternatively spliced transcripts with 23 different alternative splice protein isoforms, associated with altered expression of RNA splicing factors SF1, SRSF1, SRSF3 and SRSF7, SF3 gene repression and expression of translation initiating E1F2B family members E1F5 and EIF6, and has identified 1103 late exon, intron retention and tandem 3' TRS alternative splice events in 819 unique genes involved in protein translation, mitochondrial and ER protein degradation, metabolism, programmed cell death [57].

The effects of hypoxia on the general splicing machinery, include de-regulation of SRSF1, SRSF2, SRSF3, SAM68, HuR, hnRNPA1, hnRNPM, PRPF40B and RBM4 splice factor expression, activation and increased expression of the SR protein kinases Cdc2-like kinase-1 (CLK1) and SRPK1, that promote SR splice factor hyperphosphorylation and activity, alter splice factor intracellular localization, and capacity to interact with other proteins and pre-mRNAs, resulting in hypoxia-adapted gene transcription and promotion of tumour progression [58-63]. Amongst splice factors, hypoxia also induces alternative splicing of the ubiquitous splicing factor YT521 (YTHDC1), switching expression to two noncoding YT521 variants 2 and 3 mRNAs, functionally coupled to nonsense mediated decay, that impact the splicing of cancer-associated BRCA2 and PGR [64]. Hypoxia also significantly alters the expression of miRNAs involved in splicing and induces the expression of master IncRNA regulators of alternative splicing MALAT1, HOTAIR and LUCAT [65-71].

Hypoxia sensitive signal transduction pathways also regulate alternative splicing, resulting in tumour promoting VEGF, FGF, HGF and TGF $\beta$ signaling, ligand- independent EGFR signaling, myogenic to mitogenic conversion of insulin growth factor signaling and also specify signaling pathways use [72-76]. Signaling pathways that promote alternative splicing include: KRas promotion of PTBP1 splicing factor, Rho GTPase Rac1b, endocytic adapter NUMB and pyruvate kinase PKM2 alternative splicing; ERK promotion of splice factor phosphorylation, cancer progression-promoting CD44 exon V5 alternative splicing, fibronectin EDA exon inclusion, FAS exon 6 exclusion via SPF45 phosphorylation and SRSF1 splice factor repression via intron retention [77]; BRAF promotion of pre-mRNA processing factor phosphorylation, nucleo-cytoplasmic transport and localization, $\mathrm{Bcl}-\mathrm{xL}$ alternative splicing and repression of dominant negative A-Raf expression via hnRNPA2dependent alternative splicing; PI3K/Akt promotion of SRSF1 and SRSF7 phosphorylation, SRPK1 and SRPK2 autophosphorylation, fibronectin ED1 exon inclusion, inhibitory caspase 9 exon 3-6 exclusion, SRSF1-dependent KLF6 SV1 and SRSF5-dependent PKC $3 I$ alternative splicing, SR import into nuclear speckles and mTORC1/ S6k1-induced lipogenesis-related gene alternative splicing; Wnt promotion of SRSF3 expression, Rac1b alternative splicing, SRPK1 and SRSF1-dependent SLC39A14 alternative $4 \mathrm{~A}$ and $4 \mathrm{~B}$ exon splicing; cAMP promotion of cytoplasmic PTBP1 accumulation; WT-1 repression of SRPK1 expression and promotion of pro-angiogenic VEGFA alternative splicing; casein kinase 2 (CK2) activation of SRPK1, and calcium promotion of CaMKIVdependent hnRNPL phosphorylation and binding to RNA CARRE motifs that regulate gene-specific alternative splicing, all of which are influenced by tumour hypoxia [78].

Hypoxia also influences alternative splicing indirectly by promoting the formation of cytosolic Stress Granules, containing stalled translation pre-initiation complexes comprised of mRNAs, translation initiating factors, ribosomal subunits and RNA binding proteins, and closely related GW/P bodies that contain mRNAs, mRNA transport and modification factors, mRNA decay enzymes, translational repressor proteins. Stress granules store mRNAs, act as miRNA-mediated gene-silencing centres and contribute to cancer aggressiveness by regulating cell-death, tumourigenesis, therapeutic resistance and metastatic capacity. Stress granules regulate hypoxia-induced alternative splicing [79-82] by accumulating SRSF splicing factors and splice regulating CELF proteins that promote non-sense-mediated mRNA decay, and through stress-induced maturation of miRNAs that regulate splicing, such as miR-133 which targets hnRNP1/PTBP1 splicing factor. Stress granules also accumulate TDP43 splice factor, a component of Dicer complexes that drive stress-induced granule dynamics and miRNA biogenesis [65, 83, 84] (Fig. 4). Hypoxia is, 
therefore, a master regulator of stress-granule-associated microRNA biogenesis and activity, further influencing alternative splicing at the post-transcriptional level [85]. Hypoxia-induced alternative splicing is, therefore, highly complex, fundamental for normal physiological development, cellular differentiation and adaptive cellular responses and is subverted within the tumour context to promote metastatic progression and therapeutic resistance [86].

In the following sections, we review current concepts of the many cancer-associated hypoxia-regulated alternative splicing events that regulated tumour behaviour, organized with respect to the 10 hallmarks of cancer and the prospects for therapeutic intervention.

\section{Hypoxia-induced alternative splicing in autonomous neoplastic growth (hallmark 1)}

Tumour initiation is determined by a combination of oncogene activation and tumour suppressor inactivation, resulting in the acquisition of autonomous neoplastic growth that is promoted either by autocrine growth factor activity caused by coincidental tumour cell growth factor and growth factor receptor expression or by proliferation-promoting oncogenes damage-activated by oncoviruses, gene amplification, mutation, chromosomal translocation or alternative/aberrant pre-mRNA splicing. Rapid autonomous neoplastic growth results in tissue hypoxia at $\mathrm{O}_{2}$ diffusion distances $>70 \mu \mathrm{m}$, resulting in a pro-angiogenic hypoxic responses, cell-death and an acute inflammatory response, also required for tumour angiogenesis and clonal expansion. During this phase, tumour hypoxia-induced alternative splicing influences oncogenic activity both directly and indirectly, helping to promote and maintain tumour autonomous growth potential (Fig. 1a) [9-15].

Receptor tyrosine kinase proto-oncogenes [87] that interact with the hypoxic tumour microenvironment [88], resulting in oncogenic activation, include the neurotrophin tropomyosin-related tyrosine kinase receptor TrkA that exhibits hypoxia-induced oncogenic alternative TrkAIII splicing in human neuroblastoma, pheochromocytoma, leukemia and medullary thyroid cancer cells. TrkAIII is expressed by advanced stage primary human neuroblastomas, glioblastomas, melanomas and Merkel cell carcinomas, is characterized by cassette exon 6, 7 and 9 skipping, exhibits constitutive activation, transforms NIH3T3 cells, exhibits oncogenic activity in neuroblastoma models and prevents neural-related progenitor cell death induced by the development-regulated $N F-Y A$ alternative splice variant NF-YAx, expressed during mouse developmental stages associated with neuroblast culling and neuroblastoma suppression, suggesting potential roles in neuroblastoma initiation and hypoxiadependent progression [89-92]. Hypoxia also promotes aberrant/alternative splicing of the epithelial growth factor receptor EGFR, resulting in expression of the constitutively active, exon $2-7$ skipped EGFRvIII ( $\Delta$ Ex $2-7$ ) isoform, a proliferation promoting driver-oncogene in several tumour-types, including glioblastoma multiforme [93-95], and also induces pro-proliferation Erb4 signaling in mammary epithelial cells [96]. Hypoxia reduces the KRAS 4A to 4B (exon 4a skipped) alternative splice ratio, helping to explain predominant mutation-activated KRAS4B splice variant oncogene expression in colon tumours and cancer stem cells [36, 97, 98], and induces predominant short form MXIs alternative splicing reducing MIX1 antagonism of Nmyc-dependent proliferation of relevance to aggressive autonomous Nmyc amplified neuroblastoma growth [57]. In prostate cancer cells, hypoxia induces non-catalytic alternative splicing of the tyrosine-protein phosphatase PTPN13, augmenting tyrosine kinase-dependent signaling and proliferation, induces alternative TTC23 splicing involved in hedgehog signaling and promotes alternative RAP1GDS1 splicing, enhancing GDP/GTP exchange reactions in Rapla and $1 \mathrm{~b}$, RhoA and B and KRas G-proteins, promoting autonomous growth (Fig. 2a) [99].

In colorectal cancer cells, hypoxia augments the expression and activity of hnRNPA1, Srp55, SF/ASF, Tra-2 beta YB-1 and Sam68 splicing factors, resulting in proliferation-promoting alternative $\mathrm{CD} 44 \mathrm{v} 5$ and fibronectin EDA exon splicing; promotes LUCAT1 lncRNA expression and LUCAT/PTBP1 complexing, inducing 63 alternative splicing events (36 skipped and 27 retained exon events) in cell growth, cell cycle and G2/M checkpoint genes that augment tumour cell proliferation and colony formation [100], and induces alternative CD44v5 splicing, resulting in a novel cytokine and growth factor receptor isoform that promotes autonomous growth [77]. In breast cancer cells, hypoxia induces alternative APP splicing linked to breast cancer cell proliferation and tumorigenicity [101] and in non-small cell lung cancer cells, promotes Clk1-dependent Srp55 splicing factor phosphorylation, resulting in alternative VEGFA $_{165 b}$ splicing and autonomous growth of VEGFR2 and neuropilin-1 receptor expressing tumour cells $[102,103]$. In pancreatic cancer, tumour growth under hypoxic conditions has also been attributed to hypoxia-induced alternative splicing of tissue factor, resulting in as-TF expression, which activates carbonic anhydrase IX implicated in late-stage pancreatic cancer growth under hypoxic conditions (Fig. 2a) [104].

Hypoxia-induced alternative splicing also regulates the activity of the HIF-1-target proto-oncogene RON, an epithelial cell-specific c-MET family tyrosine kinase receptor that binds macrophage specific protein (MSP). RON exhibits hypoxia-induced oncogenic alternative splicing in breast, lung, liver, kidney, bladder, ovarian, 

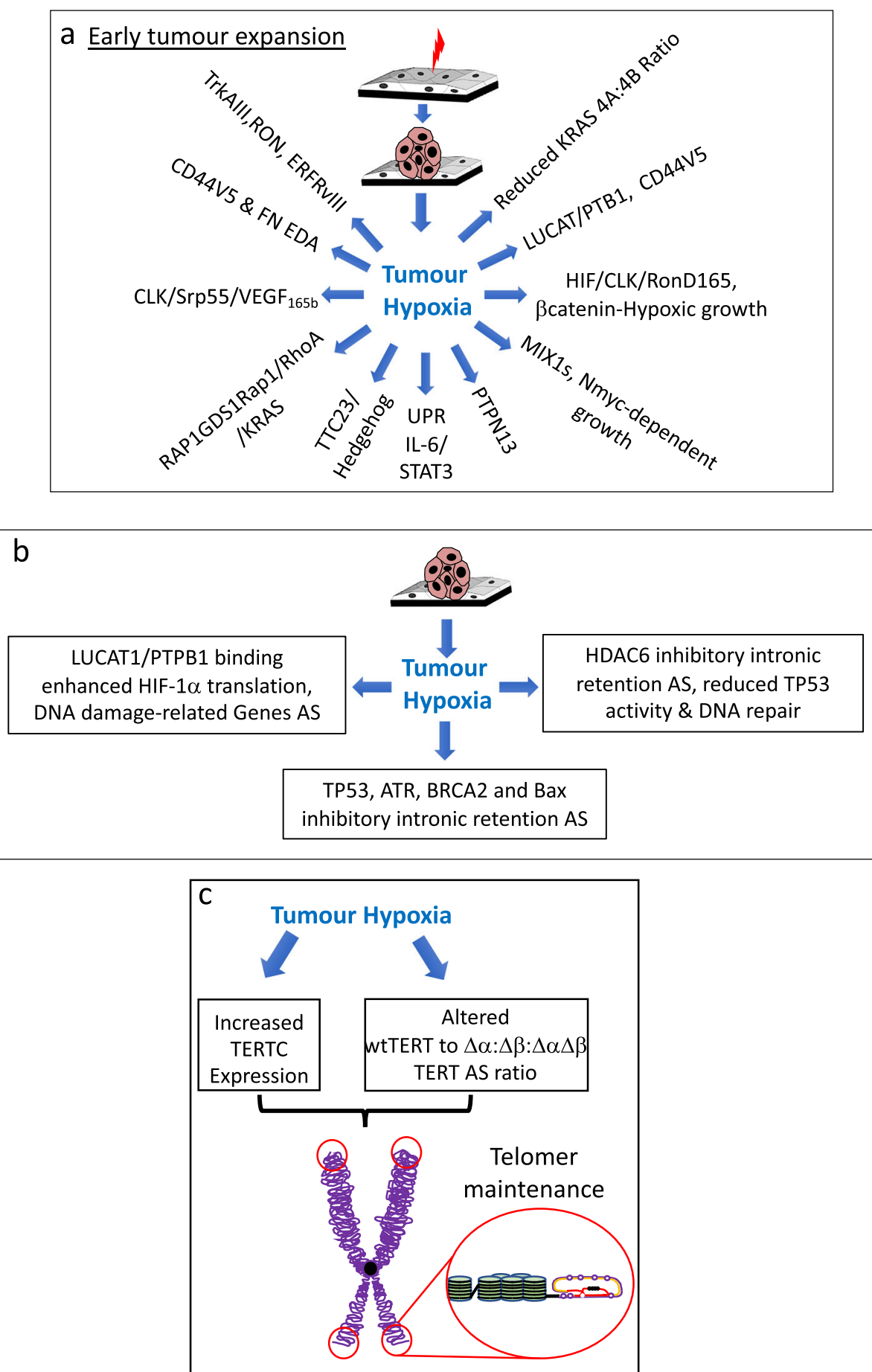

Fig. 2 Tumour hypoxia-induced alternative splicing, autonomous growth, tumour suppressor inactivation and immortalization. Schematic representations of the numerous roles played by tumour hypoxia-induced alternative splicing (AS) in: $\mathbf{a}$ autonomous neoplastic growth; $\mathbf{b}$ tumour suppressor inactivation and $\mathbf{c}$ tumour cell immortalization

colon, pancreatic, gastric and prostate carcinomas and many cancer cell lines and is composed of heterodimers of an extracellular $40 \mathrm{kda} \alpha$ chain and $150 \mathrm{kDa} \beta$ chain that contains extracellular, transmembrane and intracellular tyrosine kinase domains, derived from the same immature pre-protein. RON activation results in intracellular phosphorylation-dependent, SH2-domain adapter protein binding to the $\beta$-chain, resulting in IP3K/Akt and MAPK signaling. Alternative RON splicing is complex and results in RON $\Delta 170, \Delta 165, \Delta 160, \Delta 155$, 
$\Delta 110, \Delta 90$ and $\Delta \mathrm{i} 55$ isoforms, several of which exhibit constitutive oncogenic activation, differences in localization, opposing functions and associate with tumour progression and disease stage. Hypoxia induces oncogenic alternative RON $\Delta 165$ splicing by promoting CLK1-mediated, SF2/ASF splice factor phosphorylationdependent binding to an EES adjacent to an ESS ciselement, resulting in exon 11 skipping. Constitutive RON $\Delta 165$ activation promotes RON and $\beta$-catenin nuclear translocation, inducing cJun expression and promoting proliferation [99, 104-110]. Furthermore, increased nuclear $\beta$-catenin levels, induces TCF4 transcription factor activation, $\beta$-catenin/TCF4 complexing and the induction of cMyc, Cyclin D and c-Jun $\beta$ catenin/TCF4 target gene expression in gastric cancer cells, promoting proliferation. In addition, complexes between constitutively active RON splice variants and $\beta$ catenin also interact with HIF1 $\alpha$ to regulate HIF-1dependent transcription and tumour cell proliferation under hypoxic conditions, confirming a close relationship between hypoxia-induced alternative RON splicing, $\beta$-catenin and HIF-target genes in the regulation of autonomous tumour cell growth and tumour progression (Fig. 2a) [99, 105-111].

In addition to direct oncogene activation, hypoxiainduced alternative splicing also indirectly promotes autonomous growth by activating the unfolded protein response (UPR) in response to ER stress resulting from the accumulation of damaged and misfolded proteins $[112,113]$. The UPR is mediated by ER ATF6, PERK and Ire $1 \alpha$ proteins, the activation of which results in transient attenuation of protein synthesis, increased protein trafficking through the ER, augmented protein-folding capacity, protein degradation through ERAD and autophagy. Hypoxia-induced Ire $1 \alpha$ activation results in unconventional alternative splicing of a 26 nucleotide intron from the transcription factor $\mathrm{XBP} 1 \mathrm{u}$, resulting in expression of the frame shift XBP1s isoform, that contains a novel transcriptional activating domain and exhibits transcriptional activity. Both XBP1u and XBP1s isoforms contain leucine zipper DNA binding domains and interact to regulate nuclear translocation and transcription, and XBP1s cooperates with HIF- $1 \alpha$ to promote cell survival [114]. XBP1s binds CRE elements in proliferation, survival and protein-overload response genes, activates NF- $\mathrm{kB}, \mathrm{AP}-1$ and Myc oncogenic pathways, up-regulates the expression of 162 proliferation, protein folding and survival genes in human breast cancer cells, augments CD4K, c-Myc and Cyclin D expression to promote proliferation, complexes with and augments the transcriptional activity of c-Myc, promotes $\mathrm{PI} 3 \mathrm{~K} / \mathrm{mTOR}$-dependent osteosarcoma growth, maintains the autonomous growth potential of multiple myeloma cells [115], and promotes autocrine/paracrine STAT3- dependent growth of hepatocellular carcinoma cells [116] (Fig. 2a).

\section{Hypoxia-induced alternative splicing in tumour suppressor inactivation (hallmark 2)}

Tumourigenesis also depends upon tumour suppressor inactivation to overcome oncogene-induced senescence. Under normal circumstances, tumour suppressors, activated by cellular damage and by activated oncogenes, inhibit proliferation by activating cell-cycle checkpoints and promote temporary survival, during which attempts are made to eliminate or repair damaged molecules and, if appropriate, induce programmed cell death. In addition, tumour suppressors also help maintain cellular differentiation, intercellular adhesive interactions and contact-dependent growth inhibition [117].

Hypoxia induces alternative intron-retention splicing repressing the expression of TGF $\beta 1$, responsible for indirect retinoblastoma protein-dependent activation of the G1/S cell-cycle checkpoint [57]. In breast cancer cells, hypoxia induces splice-dependent intron-retention nonsense mediated decay (NMD) of TP53, ATR, BRCA2 and Bax tumour suppressor mRNAs, de-regulating the DNA damage response, TP53 involvement in cell cycle arrest and BAX-dependent apoptosis, TP53 expression and function, and represses TP53-target and related gene expression [56]. In colon cancer cells, hypoxia also reduces TP53 function by promoting inhibitory alternative HDAC6 intron-retention splicing, de-regulating the unfolded protein response (UPR), protein aggregate processing, altering the cell response to cytotoxic stress, reducing HDAC6-dependent TP53 binding protein-1 expression, repressing expression of the p53 target gene P21/Waf1 cell cycle inhibitor and impairing recognition of H4K20me 2 and H2AK15ub histone marks induced by DNA double strand breaks and DNA repair [118]. Whether hypoxia also promotes dominant negative inhibitory alternative delta- $\mathrm{N}$ p53, p63 and p73 splicing [119-121], remains to be confirmed.

Hypoxia also induces the expression of LUCAT1 lncRNA in cancer cells, which binds PTBP1 splicing factor resulting in alternative splicing inactivation of DNA damage-related tumour suppressors. Furthermore, PTBP1 binds the 5' UTR internal ribosome entry site in HIF $1 \alpha$ mRNA, enhancing HIF1 $\alpha$ translation, and accounts for $40-50 \%$ of hypoxia-stabilized HIF1 $\alpha$ levels [122], increasing the influence of hypoxia-induced LUCAT1/PTBP1 complexing on tumour suppressor inactivation through alternative splicing [123] (Fig. 2b).

\section{Hypoxia-induced alternative splicing in replicative immortality (hallmark 3)}

Tumour cells exhibit replication immortality and do not respect the "Hayflick" replication limit imposed on 
normal cells by telomer loss [124]. Tumour cells overcome telomer shortening by de novo telomer synthesis, which depends upon the maintenance of telomerase expression, activity, and active forms of TERT telomerase reverse transcriptase. TERT/TERTC interaction align telomerase to chromosome ends, resulting in telomer DNA addition. Hypoxia increases TERT and TERTC expression and regulates TERT alternative splicing, altering the ratio between fully spliced wild type TERT and $\Delta \alpha, \Delta \beta$ and $\Delta \alpha \Delta \beta$ TERT isoforms. In ovarian cancer cells, hypoxia induces predominant active wild typeTERT isoform expression, increasing both TERT and telomerase activity maintaining telomer length [125]. In stem cells, hypoxia promotes TERT $\Delta \alpha$ and $\Delta \beta$ alternative splicing and nuclear localization, in a stem cell maintenance mechanism, the steric inhibition of which results in differentiation, suggesting that hypoxia promotion of tumour cell alternative TERT $\Delta \alpha$ and $\Delta \beta$ splicing may not only maintain telomer length and promote immortality but also cancer staminality [126-130] (Fig. 2c).

\section{Hypoxia-induced alternative splicing in tumour angiogenesis (hallmark 4)}

Hypoxia-induced alternative splicing drives angiogenesis and is, therefore, fundamental for tumourigenicity, clonal expansion and metastatic progression [51, 131]. Under normoxic conditions, HIF- $\alpha$ subunits are proline hydroxylated by PHD prolyl-hydroxylase, complex with pVHL, elongin B, elongin $C$, Cullin2 and Rbx1 and are directed for proteasomal degradation. Hypoxia inactivation of PHD results is dissociation of HIF $\alpha / \mathrm{pVHL}$ complexes, resulting in HIF- $1 \alpha$ and HIF- $2 \alpha$ accumulation and stabilization, nuclear translocation, heterodimerization with nuclear ARNT subunits to form HIF-1 $\alpha /$ ARNT (HIF-1) and HIF-2 $\alpha$ /ARNT (HIF2) transcription factors and the induction of HIF-dependent proangiogenic alternative VEGFA and VEGFR receptor expression and splicing [33, 36-40, 44, 132, 133]. In this mechanism, hypoxia reduces the ratio of fully spliced long form HIF- $1 \alpha \mathrm{L}$ that exhibits weak transcriptional activity, to alternatively spliced short form HIF-1 $\alpha$ s, augmenting pro-angiogenic HIF-1-dependent VEGFA and VEGFR2 transcription, angiogenesis and alternative splicing of HIF-target and non-target genes [36, 134, 135]. Furthermore, hypoxia induces pro-angiogenic VEGF-A gene alternative splicing, resulting in VEGF- $\mathrm{A}_{111}$, VEGF$\mathrm{A}_{121}$, VEGF- $\mathrm{A}_{145}$, VEGF-A $\mathrm{A}_{165}$, VEGF-A $\mathrm{A}_{183}$, VEGF-A 189 and VEGF- $\mathrm{A}_{206}$ isoform expression. VEGF- $\mathrm{A}_{145}$, VEGF$\mathrm{A}_{189}$ and VEGF- $\mathrm{A}_{206}$ bind strongly to cell surfaces and matrices, VEGF- $A_{111}$ and VEGF- $A_{121}$ lack exons 6 and 7 and are diffusible, whereas VEGF- $\mathrm{A}_{165}$ is partially diffusible, matrix-associated and is a more potent angiogenesis inducer due to its heparin binding capacity that facilitates interaction with angiogenic neuropilin VEGFR co- receptors. Alternative VEGFA splice variants derived from exon 8 alternative splicing also include angiogenesis promoting VEGFA vxxa and inhibiting VEGFA $_{x x x b}$ isoforms, both of which bind VEGFR2 but only the VEGFA $_{x x x a}$ isoform activates angiogenic signaling. Alternative VEGFA $_{x x x a}$ and VEGFA $_{x x x b}$ splicing depends upon SRSF1 and SRSF6 splice factors, as SRSF6 selects the exon $8 \mathrm{a}$ distal $5^{\prime}$ splice site resulting in VEGFA $\mathrm{xxxb}$ expression and SRSF1 selects the exon 8a proximal splice site resulting in VEGFA $_{\text {xxxa }}$ expression. The hypoxia regulated splicing factor kinase SRPK1 phosphorylates SRSF1 to promote exon 8a inclusion and VEGFA $_{\text {xxxa }}$ expression, and either SRSF1 or SRPK1 repression promote VEGFA $\mathrm{x}_{\mathrm{xxxb}}$ expression. Hypoxia also promotes the expression and activation of SRSF1, SRPK1 and CLK1 splicing factor kinases, providing indirect hypoxia-inducible alternative VEGFA $_{x x x a}$ splice mechanisms for promoting angiogenesis (Fig. 3a) [51, 136].

HIF-1-target genes involved in angiogenesis also include the extracellular matrix metalloproteinase inducer EMMPRIN, which is up-regulated by hypoxia in cancer cells [137]. EMMPRIN promotes HIF- $2 \alpha$ expression and activates the AP1, ER $\alpha$ and ER $\beta$ transcriptional coregulator CAPER- $\alpha$, shifting VEGF-A 189 to VEGF-A 165 expression $[138,139]$. Hypoxia also promotes cytoplasmic translocation of ribonucleoprotein L, which competes with miR-297, miR-299 and miR-574-3p microRNAs to target the CA rich (CARE) element in the VEGFA mRNA $3^{\prime}$-UTR, providing an additional mechanism through which hypoxia can promote VEGFA isoform expression by inhibiting miRNA binding [140]. In addition, hypoxia also reduces MAX transcription factor expression through alternative intron-inclusion splicing, altering angiogenesis dependent upon MAX interaction with IncRNA EGFL7OS, involved in proangiogenic VEGF- $\mathrm{A}_{165}$ alternative splicing (Fig. 3a) [141].

In human neuroblastoma cells, the hypoxiainducible oncogenic alternative TrkAIII splice variant also promotes angiogenic alternative VEGF- $\mathrm{A}_{165}$ splicing via PI3K-signaling, increasing tumour xenograft growth and vascularization in vivo [89]. In muscle cells, hypoxia-induced VEGF expression also depends upon the alternatively spliced peroxisome proliferatoractivator receptor $\gamma$ coactivator alpha isoform NTPGC-1 $\alpha$, required for endothelial cell migration and tube formation, with implications for angiogenesis in myosarcomas [142, 143].

VEGF receptors (VEGFRs) also exhibit hypoxiainduced alternative splicing. In endothelial cells, hypoxia increases the ratio of VEGFR-1 non-signaling decoy VEGFA receptor and expression of a truncated soluble sVEGFR-1 alternative intron-retained splice variant, comprised of the first 13-14 exons, that complexes with 

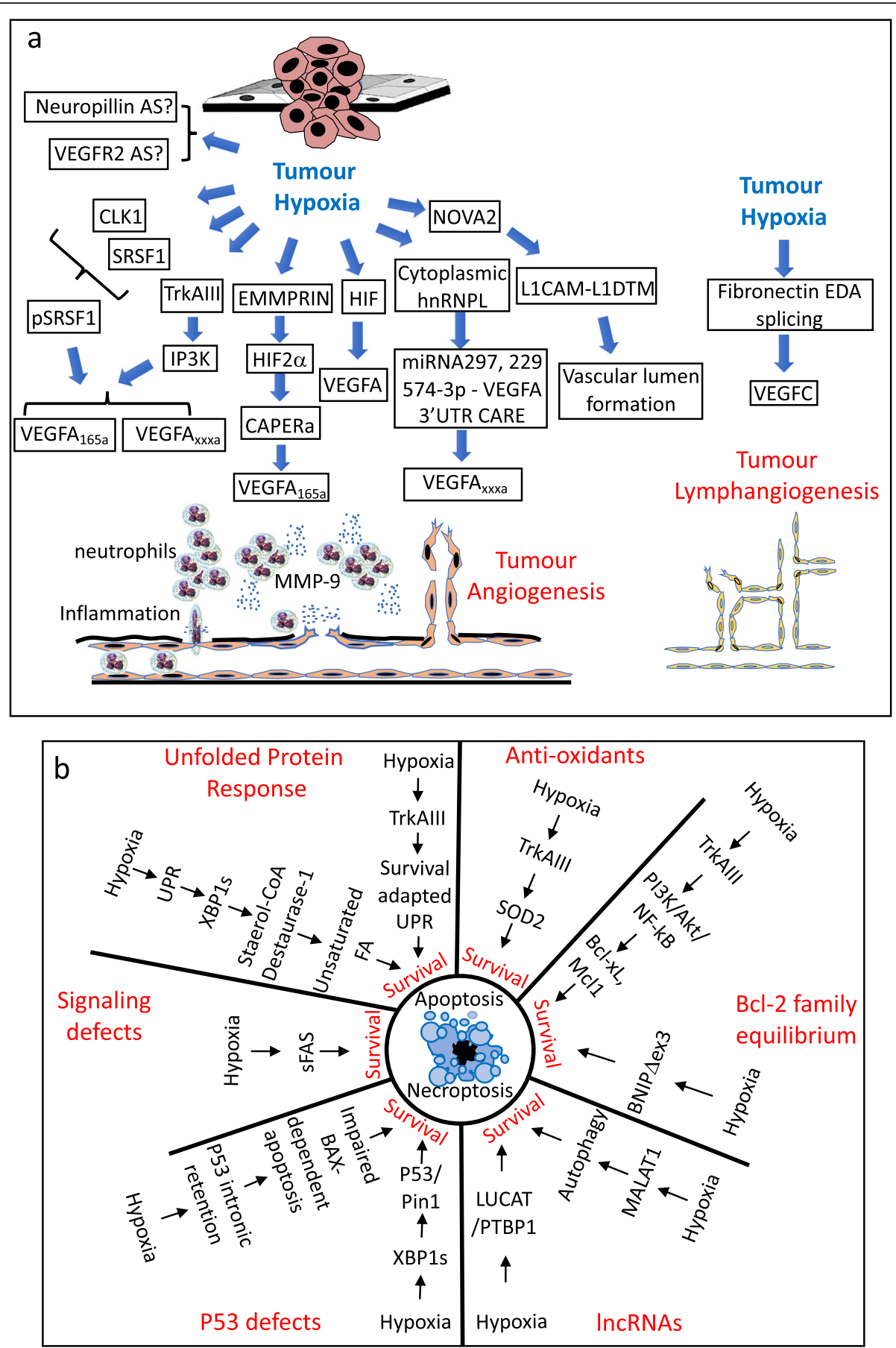

Fig. 3 Tumour hypoxia-induced alternative splicing and angiogenesis and surviving programmed cell death. Schematic representations of the role of tumour hypoxia-induced alternative splicing (AS) in: a tumour angiogenesis and $\mathbf{b}$ tumour cell evasion of programmed cell apoptotic and necroptotic cell death

VEGFR2 to reduce VEGF signaling [144]. VEGFR-2, which binds all VEGFA isoforms, is the major signaling receptor involved in angiogenesis and is also expressed as an alternative soluble sVEGFR-2 splice isoform that inhibits VEGFC/VEGFR3-dependent lymphoangiogenesis. Although a direct role for hypoxia in sVEGFR-2 and soluble s-neuropilin VEGF coreceptor [145] alternative splicing has not been reported, the sVEGFR-2 isoform is induced by inflammatory cytokines IL- 8 and IL-12 in human benign prostate hypertrophy tissue microvascular endothelial cells, suggesting an indirect role for hypoxia-induced 
inflammation in down-regulating angiogenesis in benign prostate tumours through alternative sVEGFR2 splicing [146]. Hypoxia also increases endothelial cell expression of the splice factor NOVA2, which is overexpressed in colon and ovarian cancers, and regulates endothelial cell polarity, vascular lumen formation, and also promotes expression of a soluble L1- $\Delta \mathrm{TM}$ L1CAM alternative splice isoform, which stimulates angiogenesis and promotes ovarian cancer progression $[147,148]$. The VHL HIF1 $\alpha$ inactivator and tumour suppressor also exhibits hypoxia-regulated alternative splicing, characterized by inactivating mutations in the cryptic exon (E1) deep in intron 1 that promotes excessive E1 retention and VHL protein repression, within the context of pre-neoplastic von Hippel Landau disease, leading to aberrant HIF activation (Fig. 3a) [149].

Hypoxia induction of the UPR, resulting alternative unconventional XBP1s splicing, promotes XBP1s complexing with HIF- $1 \alpha$, influencing HIF-1 transcriptional function by recruiting RNA polymerase to the promoters of pro-angiogenic VEGFA, metabolic PDK1 and GLUT1 regulators, and DDIT4 negative mTOR regulators, increasing their expression in triple-negative breast cancer (TNBC) [150]. Furthermore, hypoxia also induces an alternative intron 3-skipped splicing event in the Cysteine rich 61 (Cyr61) gene, resulting in a secreted, biologically active, pro-angiogenic Cry61 isoform that promotes breast carcinogenesis [151]. Finally, in a recent exon array analysis, 9 novel hypoxia-induced alternative splice events have been detected in the endothelial cell angiogenesis-associated cytoskeleton remodeling genes cask, itsn1, larp6, sptan1, tpm1 and robo1 [152].

Hypoxia-induced alternative splicing has also been implicated in tumor-induced lymphangiogenesis in mouse xenografts, inducing the expression of the alternative extra domain A fibronectin (EDA-FN) isoform that increases lymphangiogenesis by promoting VEGFC expression, and also promotes stem cell proliferation [153, 154], implicating hypoxia-induced alternative EDA-FN splicing in lymphatic metastatic dissemination and cancer stemness (Fig. 3a).

\section{Hypoxia-induced alternative splicing in survival, and evasion of programmed cell death (hallmark 5)}

The induction of programmed cell death is a fundamental tumour suppressing mechanism that results from two well characterized caspase-dependent apoptotic pathways, the intrinsic mitochondrial pathway and the extrinsic cell surface pathway, both of which involve the effector caspases 3 and caspase 7 [155]. Tumour cell survival and tumour progression, therefore, involves evasion of programmed cell death mechanisms also influenced by hypoxia-induced alternative splicing [156].

In brief, the intrinsic mitochondrial apoptosis pathway is activated by pro-apoptotic members of the Bcl-2 family that permeabilize the outer mitochondrial membrane, resulting in the release of mitochondrial pro-apoptotic cytochrome c, Smac/Diablo and HTR2A proteins into the cytoplasm, which inactivate cytoplasmic apoptosis inhibitory cAIP1 and cAIP2 proteins, inducing cleavageactivation of pro-apoptotic caspases, 3, 7 and 9. In contrast, the extrinsic apoptosis pathway, activated principally by NK and cytotoxic T lymphocyte populations, involves death-inducing TNF-family ligands TNF $\alpha$, FASL and TRAIL, which bind TNFR, FAS and DR4/5 TRIAL death receptors, induced on the surface of damaged cells by activated tumour suppressors, such as TP53. Death receptor ligation promotes death-inducing signaling complex formation, resulting in cleavageactivation of caspases 8 or 10, leading either to direct cell-death via effector caspases 3 and 7 or, in conditions of low caspase 8 activity, indirect activation of the intrinsic mitochondrial apoptosis pathway via caspase-8dependent tBid cleavage and mitochondrial translocation, resulting in $\mathrm{tBid} / \mathrm{Bax}$-dependent outermitochondrial membrane permeabilization and apoptosis via the mitochondrial pathway [156, 157].

With respect to the impact of hypoxia-induced alternative splicing on apoptosis [158], in breast cancer cells, chronic hypoxia promotes alternative intron 1-retention splicing in the TNF family member TNFSF13, resulting in suppression of TNFSF13 anti-apoptotic activity, implicating hypoxia-induced TNFSF13 alternative splicing in tumour suppression [56]. In hepatocellular carcinoma cells, hypoxia induces alternative exon 6 skipped FAS splicing, resulting in a soluble isoform deleted of the transmembrane domain, that inhibits Fas-dependent apoptosis [159]. Hypoxia also increases the ratio of fully spliced anti-apoptotic long Bcl-xL to alternatively sliced apoptosis-promoting short form $\mathrm{Bcl}-\mathrm{xS}$ in cancer cells [160-163], and up-regulates alternative exon 3-skipped $B N I P 3$ splicing, resulting in BNIP3 $\triangle \mathrm{Ex} 3$ isoform expression that is devoid of a mitochondrial localization signal and competes with pro-apoptotic fully spliced BNIP3 to promote survival [164-166]. In neuroblastoma cells, the hypoxia-regulated alternative TrkAIII splice variant induces survival PI3K/Akt/NF-kB signaling, increases anti-apoptotic $\mathrm{Bcl}-\mathrm{xL}$ and $\mathrm{Mcl}-1$ expression, enhances resistance to oxidative-stress by augmenting mitochondrial SOD-2 expression and activity and increases survival under conditions of acute ER-stress by activating a modified survival-adapted UPR [89, 90, 167-169]. In breast cancer cells, hypoxia-sensitive hnRNPs also induce alternative Mcl1 splicing [170], lncRNA LUCAT-1 expression, LUCAT-1 complexing with PTPB1 splice 
factor promoting survival and therapeutic-resistance [100] and alternative intron retention splicing and NMD inactivation of TP53, resulting in evasion of TP53 and BAX-dependent apoptosis [56]. In Myc-dependent cancers, UPR activation and unconventional alternative $\mathrm{XBP} 1 \mathrm{~s}$ splicing, results in XBP1s target gene transcription, increasing the expression of stearoyl-CoAdesaturase 1 and unsaturated fatty acid levels, promoting survival [113]. In osteosarcoma cells, XBP1s splicing promotes $\mathrm{PI} 3 \mathrm{~K} / \mathrm{mTOR}$ survival signaling and in glioma cell is essential for maintaining hexokinase II expression, ATP production, anti-apoptotic $\mathrm{Bcl} 2$ expression and inhibitory TP53/Pin1 complexing [115]. Consistent with a role for HIFs in cancer cell survival, UPR activation also promotes cooperation between XBP1s and HIF- $1 \alpha$ increasing survival [171]. UPR-dependent PERK activation also promotes survival by reducing protein synthesis via inhibitory e1F2 $\alpha$ phosphorylation [172], which involves alternative E1F2B5 intron-retention splicing and expression of dominant negative E1F2B5ع, which substitutes E1F2B5 in E1F2B complexes, reducing e1F2 $\alpha$-dependent translational initiation. E1F2B5 $\varepsilon$ is overexpressed in head and neck cancers, implicating hypoxia-induced E1F2B5E splicing in reducing protein expression and promoting survival during periods of hypoxia-induced acute and chronic ER stress [35]. Hypoxia also suppresses the expression exon 3 and 4 skipped Mushash-1 RNA binding protein in cancer cells, enhancing survival and resistance to cisplatin cytotoxicity [173], and the atypical splicing factor SRSF10 also plays a central role in promoting the expression of alternatively spliced stress- and apoptosisassociated genes, promoting survival under ER-stress conditions (Fig. 3b) [174].

In addition to apoptosis, programmed necroptotic tumour cell-death is also influenced by hypoxia-induced alternative splicing. This caspase-independent cell death mechanism is characterized by cellular vacuolation, cellular swelling and necrotic cell lysis is mediated by RIPK1, RIPK3 and MLKL, induced by the UPR, and also involves unconventional XPB1s splicing and hypoxiainduced autophagy, which regulate autophagosome/lysosome fusion [5, 175]. Within this context, hypoxia induced expression of the master splice-regulator IncRNA MALAT1 promotes a pro-survival autophagic response [176], associated with hypoxia repressed SRSF3 splicing factor expression, implicating yet to be defined splicing alterations in the inhibition of BECN1 autophagy suppressor expression (Fig. 3b) [177].

\section{Hypoxia-induced alternative splicing in immune evasion (hallmark 6)}

Tumour progression also depends largely upon evasion of anti-tumor immunity, and hypoxia-induced alternative splicing plays a critical role in de-regulating the antitumour immune response [178].

Hypoxia induces alternative splicing of the costimulatory TNFR family member CD137, reported in a variety of tumour cell types, results in the expression of soluble sCD137 that binds CD137L, inhibiting interaction with wtCD137 and preventing T-lymphocyte activation [179]. Hypoxia promotes alternative splicing of HLA-G human leukocyte antigen $\mathrm{G}$, a non-classical major histocompatibility complex (MHC) class I immune checkpoint molecule, resulting in expression of 4 membrane bound (HLA-G1-G4) and 3 soluble (HLAG5-G7) isoforms in melanoma, choriocarcinoma, lymphoma, glioma and other cancer cell types, that attenuate NK, cytotoxic T-cell and antigen presenting cell activity [180]. UPR-dependent unconventional alternative XBP1s splicing drives dendritic cell (DC) malfunction, is maintained within tumour microenvironments, disrupts DC homeostasis, alters local antigen-presenting capacity, promotes evasion from $\mathrm{T}$-cell mediated protective antitumour immunity and facilitates tumour progression [181]. The hypoxia-regulated PDL1 suppressor of adaptive immunity is also expressed as 2 soluble alternative splice variants in human non-small cell lung carcinoma, in association with mutation of TDP-43 splicing factor, which regulates PD-L1 expression and splicing. Both soluble PD-L1 isoforms bind PD-1, act as PD-1 decoys, promote lymphocyte exhaustion and enhance resistance to anti-PD-L1 immune-therapy (Fig. 4a) [182, 183].

\section{Hypoxia-induced alternative splicing in metabolic reprogramming (hallmark 7)}

Hypoxia modifies metabolism and is a critical component in maintaining the glycolytic metabo-type that characterizes malignant tumour progression [184].

Otto Warburg was the first to observe that malignant tumours rely upon glycolysis for their metabolic and anabolic needs and process glucose to pyruvate and lactate via glycolysis [1]. Hypoxia-induced alternative pre-mRNA splicing influence on tumour metabolic reprogramming takes its initial cues from physiological metabolic reprogramming under anaerobic conditions, which initiates with HIF1 $\alpha$ stabilization and HIF1 promotion of glycolysis-promoting alternative pyruvate kinase PKM2 splice variant isoform expression, at the expense of the oxidative phosphorylation-promoting PKM1 isoform, resulting in a metabolic shift to glycolysis. Although malignant tumours eventually acquire a continuous glycolytic metabolic state under anaerobic conditions, during tumourigenesis and throughout tumour progression, hypoxia remains a fundamental condition that promotes glycolysis in both normal and neoplastic tumour components. 

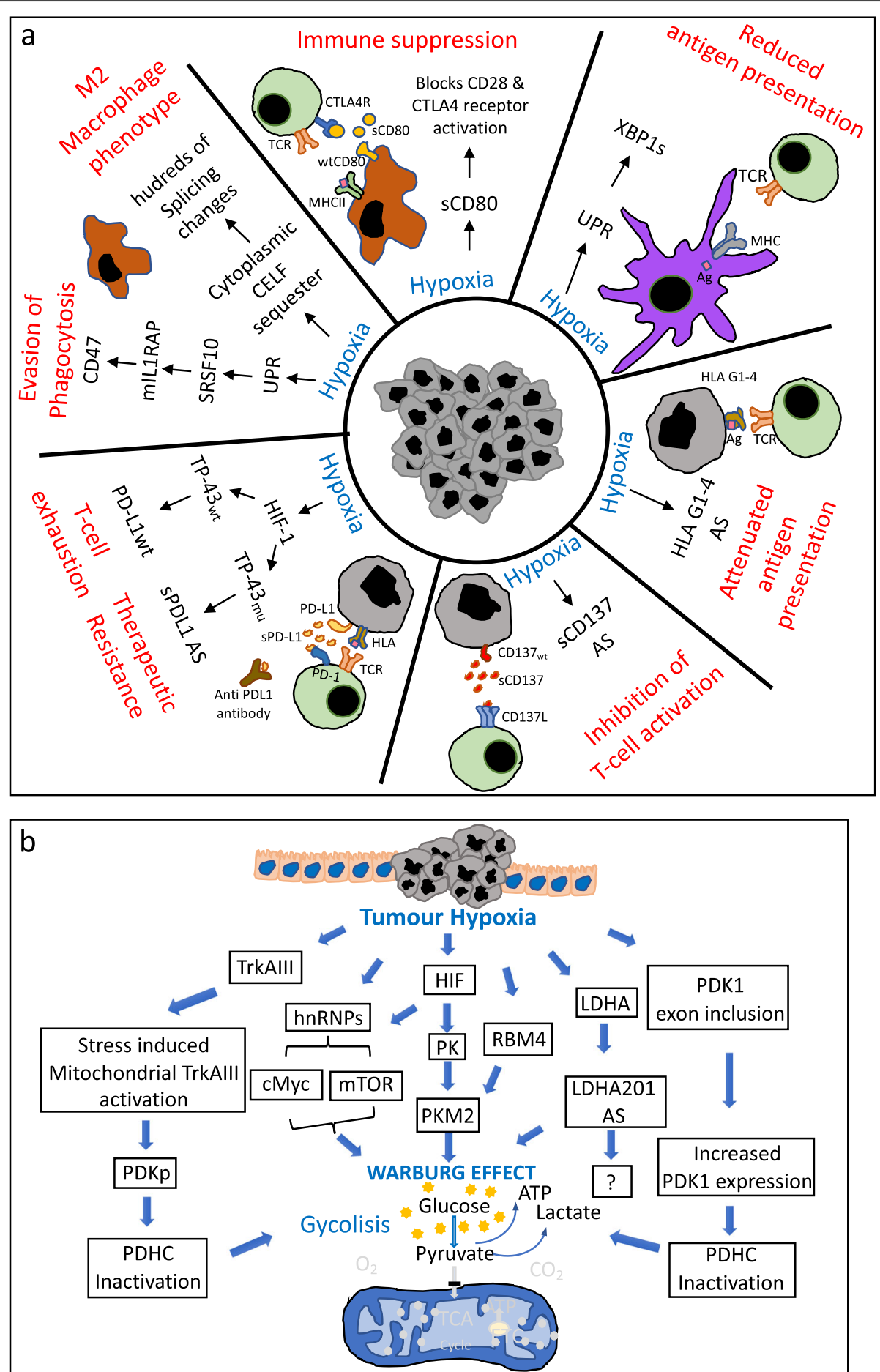

Fig. 4 Tumour hypoxia-induced alternative splicing (AS), inflammation, immunity and metabolic adaptation. Schematic representations of tumour hypoxia-induced alternative splicing mechanisms that: a protect tumour cells from anti-tumour immunity and inflammation and; $\mathbf{b}$ that impacts tumour metabolism to promote the glycolytic "Warburg Effect"

Pyruvate kinase (PK) catalyzes phosphate transfer from phosphoenolpyruvate to ADP, producing 1 molecule of pyruvate and 1 molecule of ATP, providing carbons for the mitochondrial citric acid cycle. The $P K$ gene exhibits alternative splicing and is expressed as liver PKL, erythrocyte PKR, adult tissue PKM1 and lung, adult stem cell, embryonic and tumour PKM2 isoforms. PKM1 and PKM2 represents alternative splice variants 
of the same 12 exon transcript, in which exons 9 and 10 are mutually exclusive. Hypoxia promotes HIF-1dependent PK expression and alternative PKM2 splicing $[185,186]$. PMK2 exhibits weaker enzymatic activity than PMK1, resulting in accumulation of glycolytic intermediates for biomolecular synthesis, providing an initial hypoxia-induced alternative splice input for metabolic reprograming during tumour initiation, early expansion and progression. This evolves into morepermanent HIF-dependent alternative PKM2 splicing under aerobic conditions, as oncogenes are activated that promote constitutive hypoxia-independent HIF expression and activity, alter hnRNPs or c-Myc expression or induce mTOR signaling, resulting in the constitutive PKM2 expression that characterizes the "Warburg effect" in a wide range of malignancies [1, 187]. The hypoxia-regulated RBM4 splicing factor also promotes alternative PKM2 splicing in embryonic stem cells, with potential implications for cancer stem cell metabolism (Fig. 4b) [188].

Pyruvate, the end product of glycolysis, is a major substrate for oxidative metabolism and a branching point for glucose, lactate, fatty acid and amino acid synthesis $[189,190]$. During oxidative metabolism, cytosolic pyruvate is transported to the inner mitochondrial membrane by MPC1 and MPC2 pyruvate carriers, where it is oxidized by the pyruvate dehydrogenase complex (PDHC) to Acetyl CoA prior to entering the TCA cycle, in which carbons are converted to $\mathrm{CO} 2$ and energy (NADH, NADPH and ATP) [187, 191]. Mitochondrial PDHC links and controls the flux of pyruvate from glycolysis to the TCA cycle and catalyzes irreversible pyruvate conversion to acetyl-CoA. Hypoxia inactivates PDHC, providing pyruvate for lactate dehydrogenase A (LDHA), which catalyzes reversible conversion to lactic acid [192]. LDHA is a HIF-target gene and key to the "Warburg effect", producing lactate and NAD+ for both aerobic and anaerobic glycolysis, this enzyme is upregulated by hypoxia and exhibits hypoxia-induced alternative splicing. In breast cancer cells, acute and chronic hypoxia promote alternative LDHA-001 (alternative first exon) splicing and reduce LDHA-201 (intron 1-retained) isoform expression, leading to loss of LDHA-201 expression through NMD. However, the influence of this on metabolism remains to be elucidated (Fig. 4b )[56].

The hypoxia-regulated alternative TrkAIII splice variant also promotes stress-induced metabolic reprogramming in human neuroblastoma cells, by localizing to mitochondria under non-stressed conditions in inactive form, where it exhibits mitochondrial internalization and cleavage-dependent activation under conditions of ER stress, resulting in tyrosine phosphorylation of pyruvate dehydrogenase kinase (PDK1) and glycolytic metabolic re-programming [193].
Hypoxia-induced PDK2 activation also associates with hypoxia-induced alternative BNIP3 $\Delta \mathrm{ex} 3$ splicing, linking metabolic re-programming to survival $[164,165,194]$, and the hypoxia-regulated SR protein SC35 induces aberrant E1a pyruvate dehydrogenase splicing promoting acidosis within the hypoxic microenvironment [195]. In hepatocellular carcinoma cells, HIF-dependent alternative exon inclusion splicing of pyruvate dehydrogenase kinase PDK1 is also induced by hypoxia, promoting glycolysis via this important pyruvate dehydrogenase complex inhibitor (Fig. 4b) [36].

\section{Hypoxia-induced alternative splicing in EMT, tumour invasion, metastasis and stemness (hallmark 8)}

Tumour invasion and metastasis is a multistep process in the majority of carcinomas and is characterized by tumour cell breaching of basement membrane barriers, motility, invasion of local tissues, systemic dissemination via lymphatic and blood vessels, arrest in microvasculature of distant organs and metastatic growth. This process is facilitated by the accumulation of genetic mutations and is promoted by hypoxia and hypoxiainduced alternative splicing.

In the majority of carcinomas, this multi-step process initiates with an adaptive metaplastic transition from an epithelial to mesenchymal phenotype (EMT), characterized by hypoxia-triggered loss of epithelial cell polarity and cell-cell adhesive interactions, acquisition of migratory invasive behavior and a gene expression profile more characteristic of multipotent mesenchymal stromal cells [196]. Several hypoxia-induced alternative splicing events have been closely linked to EMT. In hepatocarcinoma cells, hypoxia induces alternative splicing of the membrane and actin-associated protein Supervillin, involved in actin filament assembly, cell spreading, lamellipodia extension and regulation of focal adhesions, resulting in V4 and V5 alternatively spliced isoforms that promote RhoA/ROCK-ERK/p38-dependent EMT [197]. In a variety of cancer cell types, hypoxia induces expression of lncRNAs MALAT1, ZEB2-AS1 and HOTAIR, which are master regulators of alternative splicing, miRNA sponging, EMT, invasion, migration, cancer staminality and metastatic growth [66, 68-70, 198-203]. MALAT-1 localizes to nuclear speckle pre-mRNA splicing sites, interacts with SRSF1, SRSF2, and SRSF3 splice factors, influences SF1, U2AF65, SF3a60, and U2B distribution and modulates SR splice factor phosphorylation [204, 205], resulting in gene-specific EMT-promoting alternative splicing and metastatic progression in colorectal and triple negative breast cancers $[67,206]$. Hypoxia-induced HOTAIR expression interacts with the B1 component of the heterogeneous ribonuclear matchmaker protein HnRNP A2/B1 and regulates RNA/ 
snRNA annealing to specific pre-mRNA splicing targets, altering splicing and promoting EMT, tumour invasion and metastasis [207]. Hypoxia also induces the EMTpromoting transcription factor Snail [208, 209], which stimulates ZEB2-AS1 lncRNA expression, preventing ZEB2 mRNA intron 1 alternative splicing, a critical event in ZEB2 protein expression [199] and ZEB2dependent repression of E-Cadherin expression, EMT and proliferation, and also impairs apoptosis by repressing Bax, caspase 3 and caspase 9 expression (Fig. 5a) [210].

The HIF-1-target proto-oncogene RON has also been implicated in hypoxia-induced EMT, tumor invasion and metastasis. Hypoxia induced oncogenic alternative RON splicing and activation promotes CLK1-medited SF2/ ASF splice factor phosphorylation-dependent reduction

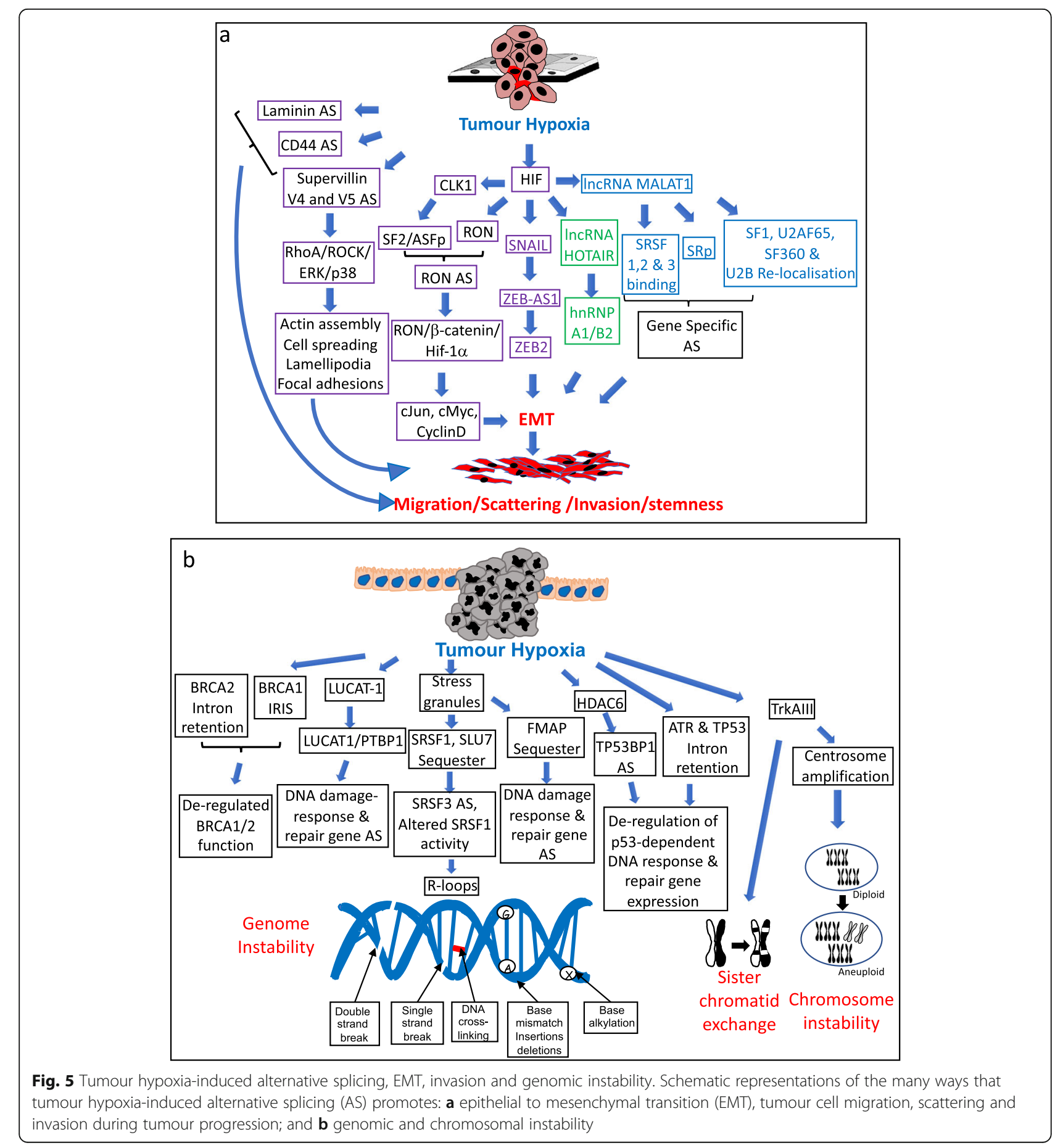


in E-cadherin expression, and promotes actin reorganization and vimentin expression, resulting in EMT, invasion and metastasis. Hypoxia induced oncogenic alternative spliced RON isoforms associate with breast, lung, liver, kidney, bladder, ovarian, colon, pancreatic, gastric and prostate carcinoma progression and, in contrast to dominant negative $\mathrm{RON}$ isoforms, in general, promote EMT, tumour cell migration, scattering, invasion and metastatic progression (Fig. 5a )[99].

Hypoxia-induced EMT also associates with repression of ESRP1 splice factor expression, resulting in $\alpha 6 \mathrm{~B}$ integrin subunit alternative splicing and the generation of $\alpha 6 \mathrm{~B} \beta 1$ integrin receptors that characterize cancer stem cell phenotypes [211, 212]. At present, however, it is unclear whether hypoxia is also responsible for expression of the novel E-Cadherin splice variant Ecadvar, detected in several cancer cell lines, which down regulates wild type E-cadherin expression in breast cancer cells, decreasing cell-cell interactions, increasing motility and enhancing invasive capacity [213].

EMT also associates with a progressively more cancer stem cell-like phenotype [214-216], reported to involve interactions between HIF-1 $\alpha, \mathrm{ZEB} 1$ and the soluble sCD44 splice variant, implicating hypoxia-regulated alternative splicing in cancer stem cell promotion [217, 218]. Within this context, severe hypoxia exerts cellspecific effects upon gene expression and alternative splicing [219], including the expression of DCLK1 splice variants that promote stem cell self-renewal and drugresistance [220], and the hypoxia-induced alternative TrkAIII splice variant that promotes and maintains a cancer stem cell-like phenotype in human neuroblastoma cells (Fig. 5a) [168, 221].

In head and neck cancers, hypoxia-induced laminin $\alpha 3$ chain alternative splicing and expression of the splice variant LAMA3 isoform has been implicated in tumour invasion and metastatic progression [222] as has hypoxia alteration of the PTBP-1-regulated alternative splice equilibrium between invasion and motility promoting protein cortactin and its invasion/ migration inhibiting alternative exon 11 inclusion spliced isoform (Fig. 5a ) [223, 224].

\section{Hypoxia-induced alternative splicing in tumour- associated inflammation (hallmark 9)}

Tumour initiation, rapid expansion and microenvironmental hypoxia, are accompanied by an acute inflammatory response that is regulated by complex $N F-k B$ signaling [225]. Tumours recruit inflammatory leucocyte and lymphocyte populations that are essential for tumour angiogenesis, which are manipulated and subverted within the tumour microenvironment to promote rather than impede tumor progression. In this process, tumor chemical and cellular micro-environments interact to promote tumor promoting N1 neutrophil and M2 macrophage phenotypes, which can be reverted to tumour inhibiting N2 and M1 phenotypes by relieving tumour hypoxia [226, 227]. Tumour associated macrophages (TAMs) make up significant proportions of most tumours, accumulate within hypoxic/necrotic areas in endometrial, breast, prostate and ovarian carcinomas and promote aggressive tumor behavior and metastatic progression [228]. Hypoxia suppresses the M1 macrophage anti-tumor pro-inflammatory phenotype [229-233] by promoting cytoplasmic stress granule sequestration of splicing factors, including CELF1, helping to explain why M1 macrophages express hundreds of spliced RNAs not expressed by M2 tumour-promoting TAMs, implicating hypoxia-induced cytoplasmic CLEF-1 retention in promoting the alternative splicing events that promote and maintain the M2 macrophage tumour promoting phenotype [234]. Hypoxia also suppresses adaptive immunity by reducing cell surface expression of the monocyte/macrophage co-stimulatory molecule CD80 and promoting alternative CD80 splicing, resulting in expression of a soluble sCD80 isoform that binds and blocks CD28 and CTLA4 receptor activation, resulting in immune suppression [235]. UPR-induced unconventional XBP1s splicing increases hepatic proinflammatory cytokine IL-6 expression and secretion, promoting autocrine/paracrine STAT3 activationdependent hepatocellular carcinoma growth [116], and has been implicated in antagonizing NF-kB-dependent pro-inflammatory cytokine expression and secretion to repress acute inflammation in some cancers, reducing anti-tumoral activity [236]. In cervical tumour cells, the UPR also induces oncogenic activation of the atypical splicing factor SRSF10, resulting in IL1-RAP alternative exon 13 inclusion, membrane associated mIL1-RAP expression and IL1 $\beta /$ IL1R1/mIL1RAP-dependent expression of CD47, the "don't eat me" inhibitor of macrophage phagocytosis, identifying a UPR/SRSF10/ mIL1RAP/CD47-dependent tumour-promoting axis (Fig. 4 a )[237].

\section{Hypoxia-induced alternative splicing in tumour genetic instability (hallmark 10)}

Genetic instability underpins all stages of cancer, from tumour initiation to metastatic disease, and is both directly and indirectly influenced by tumour hypoxiainduced alternative splicing.

Hypoxia induces stress-dependent re-localization of RNA binding proteins, spliceosome components and splicing factors to stress granules in an indirect mechanism that promotes R-loop formation, as a co-lateral active transcriptional consequence of nascent RNA hybridization to the DNA template. R-loops destabilize the genome, halt DNA replication, promote double 
strand DNA breaks and are prevented by RNaseH1, RNA-DNA helicases, topoisomerases, mRNA ribonucleoprotein (mRNP) biogenesis factors and by SRSF1 and Slu7 splicing factors. Hypoxia promotes SRSF1 and Slu7 cytoplasmic stress granules sequestration, reducing nuclear levels and resulting in mitotic aberrations, Rloop formation and genomic instability, characterized by DNA-damage, mitotic derangement and sister chromatid cohesion, dependent upon aberrant SRSF1 (ASF/SF2) splicing factor activity, alternative SRSF3 truncated SRp20 and -TR isoforms expression [238-240]. Hypoxia also promotes cytoplasmic stress granule sequestration of the spliceosome component MFAP1 [241], reducing nuclear MFAP1 levels, resulting in alternative splicing of DNA damage response and DNA repair genes that results in genomic instability [242]. Additional mechanisms by which hypoxia-regulated alternative splicing promotes genetic instability, include induction of LUCAT1 expression and complexing with PTBP1, resulting in inhibitory alternative DNA damage-related gene splicing, and inhibitory intron-retention alternative splicing of DNA damage and DNA repair pathway genes in human colorectal and breast cancer cells [56]. Hypoxia also switches DNA damage response pathway coding transcripts to non-coding intron-retained alternative spliced transcripts in genes, such as HDAC6, a cytotoxic response regulator that regulates inhibitory alternative splicing of the TP53BP1 p53 binding protein and TP53 co-factor, resulting in de-regulated double strand DNA repair in colorectal cancers, highlighting a predominant role for hypoxia-induced alternative splicing in deregulating the DNA damage and DNA repair responses (Fig. 5b )[118].

In breast cancer cells, hypoxia also triggers alternative BRCA1-IRIS splicing in hypoxic/necrotic niches, promoting tumour progression by de-regulating wtBRCA1 function [243-247], and also inactivates TP53, ATR, BRCA2 and Bax tumour suppressors by promoting alternative intronic retention splicing and NMD, reducing TP53, ATR and BRCA2 involvement in the DNA damage response [56].

Finally, expression of the hypoxia-regulated alternative TrkAIII splice variant in neuroblastoma cells augments sister chromatid exchanges and re-localizes to centrosomes in active form, inducing polo kinase 4 activation, centrosome amplification, enhanced tubulin polymerization and chromosomal instability (Fig. 5b )[221, 248].

\section{Therapeutic prospects}

Between 10 and $30 \%$ of solid tumours are characterized by fluctuating acute and chronic hypoxia, resulting in cellular hypoxic responses that include alternative premRNA splicing and the expression of novel protein isoforms that promote tumour progression and impact therapeutic efficacy. Hypoxic regions of tumours are populated by slowly dividing tumour cells that escape death induced by cytotoxic agents that target proliferating cells and are infiltrated by immature tortuous permeable blood and lymphatic vasculatures that increase tumour interstitial hypertension, a potent force for drug expulsion. Tumour glycolytic adaptation renders the hypoxic tumour microenvironment acidic and reducing, further de-regulating inflammatory and immune cell recruitment and function, enhancing multidrug resistance through elevated expression of p-glycoprotein multidrug transporter, which combined with mechanisms to evade programmed cell death, greatly reduce therapeutic efficacy. Considering the many roles of hypoxia-induced alternative splicing in tumour pathogenesis and progression, targeting tumour microenvironmental hypoxia, the tumour microvasculature, hypoxic responses, hypoxiainduced alternative splicing and tumour promoting alternative splice protein isoforms, are all of potential therapeutic importance [249-257].

\section{Targeting tumour hypoxia - tumour reoxygenation and vascular normalization}

Therapeutic efficacy can be enhanced by interfering with or reprogramming the hypoxic tumour niche to improve drug efficacy [258]. Tumour reoxygenation improves fractionated radiotherapeutic efficacy and can be achieved by hyperbaric oxygenation, intra-tumoral injection of lipid stabilized oxygen microbubbles that enhance tumour oxygenation and radiotherapeutic efficacy in rodent tumour models $[259,260]$, by nanoparticlemediated tumor reoxygenation and oxygen-generating methods [261] or by artificial red cells [8].

"Normalization" of the aberrant tumour vasculature is also emerging as an alternative way to improve tumour oxygenation, reduce tumour progression and therapeutic efficacy. This stems from observations that vascular destruction by anti-angiogenic agents promotes tumour hypoxia, reduces therapeutic efficacy and facilitates metastatic progression. The tumour microvasculature is immature, permeable, tortuous, haphazard, exhibits aberrant basement membranes and lacks a complete repertoire of cellular and matrix components required for vascular maturation and function. This flawed system increases interstitial hypertension resulting in drug expulsion, inducing selection of more aggressive phenotypes through adaptation to hypoxia, which is facilitated by hypoxia-induced alternative splicing. Vascular "Normalization" requires the delicate rebalancing of angiogenic factor/inhibitor equilibria and can be achieved by careful selection and dosage of antiangiogenic agents. This has been demonstrated by down regulating VEGFA expression in a human tumour mouse xenograft model, resulting in the pruning immature permeable vessels, re- 
modeling a less-permeable, less-tortuous vasculature with more pericytes and near-normal basement membrane, responsible for increasing tumour oxygenation, decreasing tumour interstitial pressure and improving drug penetration [243]. Consistent with this, patients treated with the monoclonal VEGFA inhibitor bevacizumab or with small molecule PTK787 and SU6668 VEGFR tyrosine kinase inhibitors, exhibit improved tumour blood flow, reduced tumour microvascular density, volume and tumour interstitial pressure but do not exhibit decreased radioactive tracer uptake, indicating improved drug-uptake potential. This effect, however, may be short lived and requires better understanding of the molecular mechanisms involved in order to prolong this effect [245]. PHD2 inhibition also promotes tumour vascular "normalization", restoring tumor oxygenation, normalizing the vascular endothelium and inhibiting metastatic progression (Fig. 6a )[262].

\section{Targeting hypoxia-induced alternative splicing}

Tumour promoting subversion of pre-mRNA splicing by hypoxia, resulting in oncogene activation, tumour suppressor inactivation, immortalization, metabolic adaptation, evasion of programmed cell death and anti-tumour immunity, angiogenesis, tumour-promoting inflammation and genetic instability, not only depends upon specific alternatively spliced protein isoforms but also specific spliceosome components, splicing factors, splice factor kinases and splicing, all of which represent potential therapeutic targets.

\section{HIF inhibitors}

HIF transcription factors are activated by tumour hypoxia, promote HIF-target expression and alternative splicing of HIF-target and non-HIF target genes [36]. Hypoxia inactivation of PHD proline hydroxylase, results in dissociation of HIF $\alpha / V H L-V E C$ complexes, HIF $\alpha$ stabilization, nuclear translocation and heterodimerization with ARNT/HIF $\beta$ components [37, 38], identifying many relevant therapeutic targets.

HIF inhibitors fall into different categories and include inhibitors of HIF mRNA and protein expression, inhibitors of HIF dimerization, DNA-binding and transcriptional activity and promoters of HIF degradation, with some inhibitors exhibiting more than one function. Inhibitors of HIF-1 mRNA and protein expression, include: lncRNA PIN1-v2 [46], S-TRPM2 calciumpermeable ion channel short variant [263] and EZN2698 and EZN-2208 HIF-1 $\alpha$ antisense oligonucleotides (ASOs) that inhibit HIF- $1 \alpha$ mRNA and protein expression $[264,265]$. The topoisomerase inhibitor, camptothecin analogue, topecan inhibits Hif- $1 \alpha$ protein translation and function [266], the natural flavonoid Chrysin inhibits HIF $\alpha$ protein expression, by blocking Akt signaling [267], soybean glyceollin phytoalexins inhibit HIF-1 $\alpha$ protein expression by blocking the PI3K/Akt/mTOR pathway [268], the estrogen metabolite 2-methoxyestrodiol inhibits Hif- $1 \alpha$ and Hif- $2 \alpha$ protein synthesis, nuclear translocation and transcriptional activity and is currently under clinical evaluation in a variety of tumour types [269], and the small molecule inhibitor KC7F2 inhibits Hif- $1 \alpha$ protein but not mRNA synthesis by repressing eukaryotic translation initiating factor $4 \mathrm{E}$ binding protein and p70 S6 kinase [270].

Inhibitors of Hif- $1 \alpha$ accumulation and transcriptional activity, include the Hsp90 inhibitors GA, 17-AAG, 17DMAG and EC154 that promote VHL-dependent HIF- $\alpha$ degradation $[271,272]$, the HDAC inhibitor virinostat that promotes HIF $\alpha$ degradation [273], the small molecule PX12 that inhibits Hif- $1 \alpha$ accumulation by targeting thioredoxin-1 [274, 275], the small molecular inhibitor LW6 that promotes VHL-dependent Hif- $1 \alpha$ degradation [276] and BAY87-2243 that suppresses HIF- $1 \alpha$ and Hif- $2 \alpha$ protein accumulation by inhibiting mitochondrial complex-1 (stopped in phase 1 trials for safety reasons) [277, 278].

Inhibitors of HIF dimerization include cyclic CLLFVY that binds the HIF-1 $\alpha$ PAS-B domain disrupting dimerization, transcriptional function and hypoxic response in tumour cells [279], TC-S7009 [280], an unreferenced small molecular PT2353 nanomolar HIF-2 but not HIF-1 inhibitor that impairs HIF DNA-binding and HIF-2 dependent hypoxic responses, and the antiseptic dye acriflavine that inhibits HIF-1 and HIF-2 and prevents HIF-1 dimerization [281]. The DNA intercalating anthracyclins Doxorubicin and daurubicin also inhibit HIF binding to HREs in gene promoters [282], and echinomycin (NSC-13502) prevents HIF-1 binding to the VEGF promoter core HRE sequence 5' -CGTG-3' [283].

HIF transcriptional Inhibitors, include: chetomin dithio-diketopiperizine that impedes HIF- $1 \alpha$ interaction with its transcriptional activating histone acetyltransferase p300 co-factor and increases the radiosensitivity of human fibrosarcoma cells [284]; idenopyrasole 21 that inhibits HIF- 1 transcriptional activity but not HIF- $1 \alpha$ accumulation or dimerization [285]; YC-1 platelet aggregation inhibitor that disassociates HIF- $1 \alpha /$ p300 complexes, represses HIF transcriptional activity and reduces HIF$1 \alpha$ protein accumulation [286]; FM19G11 that inhibits HIF transcriptional activation by impairing interaction with p300 [287]; small molecule NSC-607097 that inhibits HIF-1 transcriptional activity [288], and IDF11774 that prevents HIF- $1 \alpha$ accumulation, regulates cancer metabolism, suppresses tumour growth in vitro and in vivo and is a clinical cancer therapy candidate [289]. Finally, the fungal product Chaetocin has been shown to de-regulate HIF- $1 \alpha$ pre-mRNA splicing and inhibit hepatoma and ovarian cancer growth in cancer models by reducing angiogenesis (Fig. 6b) [290, 291]. 


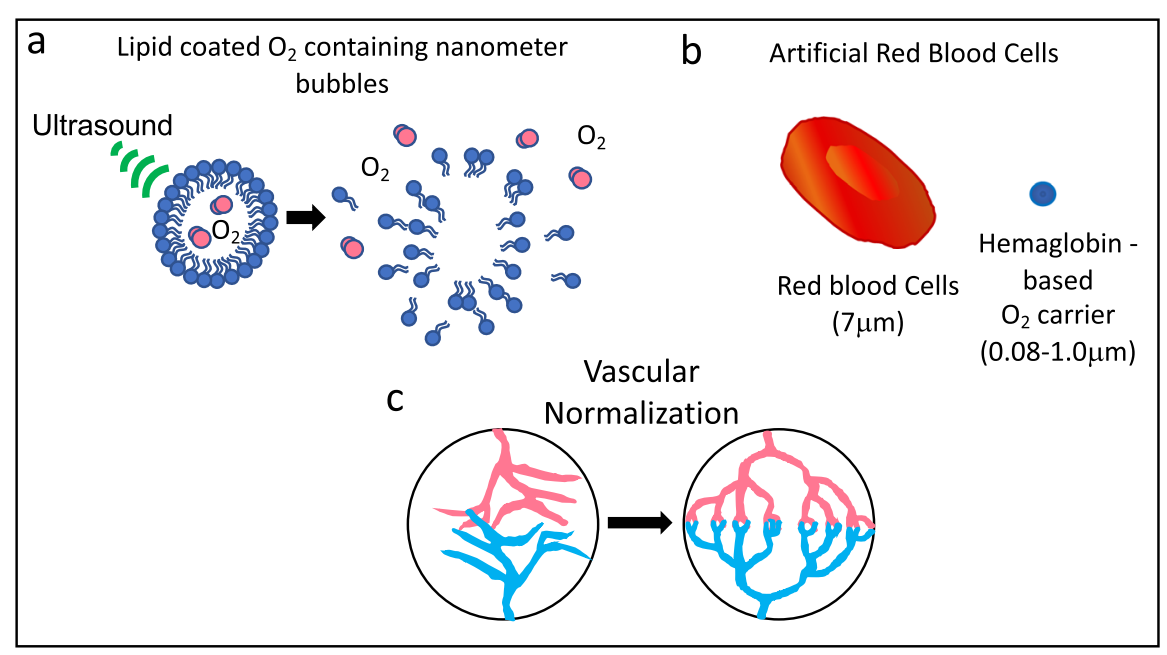

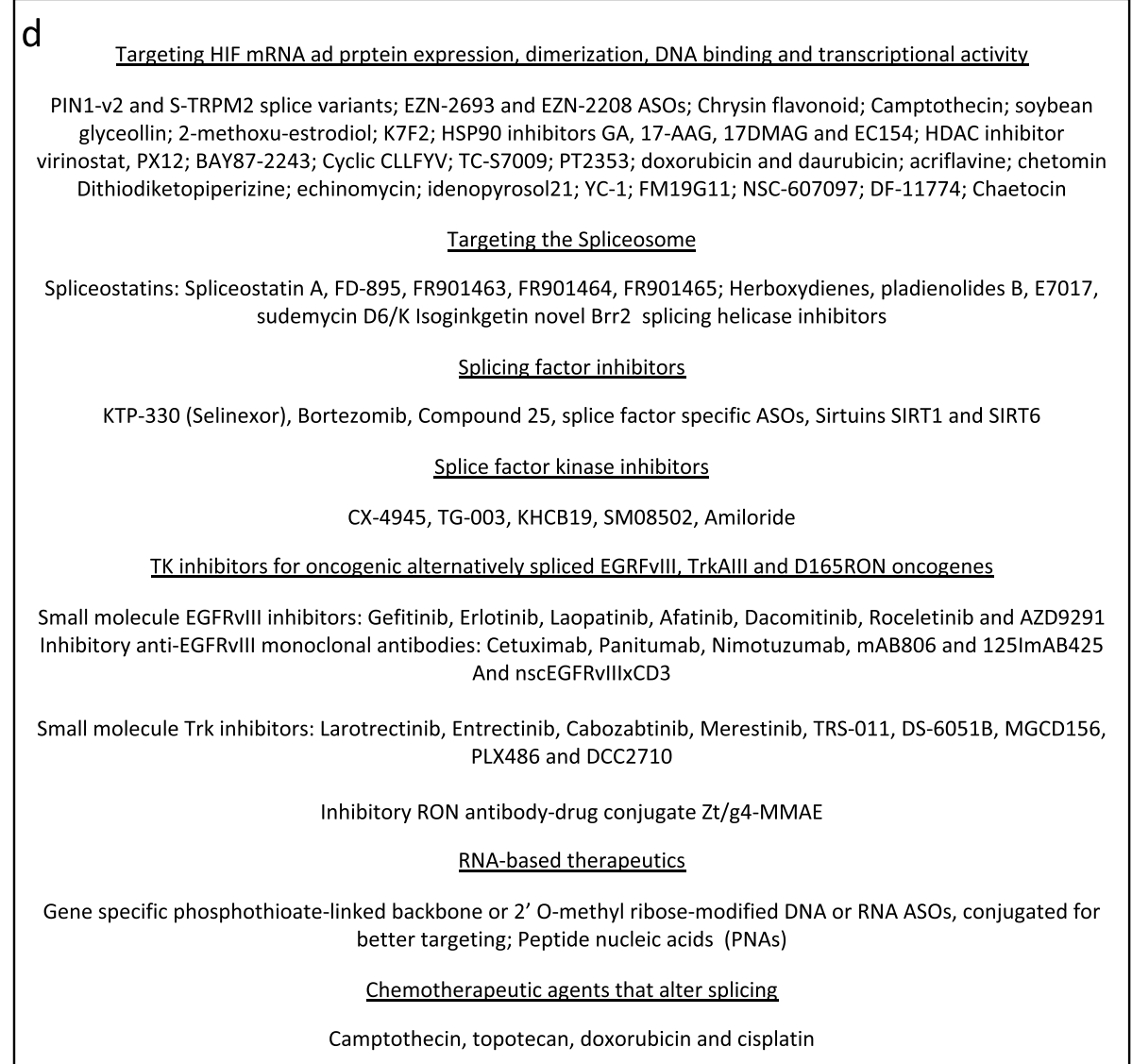

Fig. 6 Tumour hypoxia-induced alternative splicing: Therapeutic approaches. Schematic representation of the potential therapeutic approaches for reducing tumour hypoxia and subsequent tumour promoting alternative splicing, including a The use of lipid coated oxygen containing microbubble or nanoparticles that can be induced to release oxygen within hypoxic tissue by ultrasound (and also by diffusion, not shown); $\mathbf{b}$ Artificial red blood cell hemoglobin based oxygen carrying particles of 0.8-1.0 $\mu \mathrm{m}$ which reach places that $7 \mu \mathrm{M}$ red blood cells cannot; $\mathbf{c}$ Vascular normalization by subtle re-equilibration of angiogenic equilibria, and $\mathbf{d}$ Small molecule inhibitors and modified antisense oligonucleotides and peptide nucleic acids to target spliceosome components, splicing factors, splice factor kinases, hypoxia induced alternatively spliced tyrosine kinase oncogenes and chemotherapeutic agents that alter splicing 


\section{Targeting the spliceosome}

Targeting the spliceosome is an alternative way to inhibit tumour-promoting, hypoxia-induced alternative splicing.

Bacterial products that bind the SF3B component of U2 snRNP and interrupt spliceosome assembly, include: the spliceostatins, spliceostatin A, FD-895 and the derivatives FR901463, FR901464 and FR901465; sudemycins, from pseudomonas [292]; herboxidienes, from streptomyces A7847, and pladienolide B and its E7017 analogue, from streptomyces platensis Mer-11,107. These inhibitors induce cell cycle arrest, cytotoxicity and inhibit $\approx 10 \%$ of canonical splicing events, suggesting that only weaker splice sites are influenced by spliceosome inhibitors. E7017, spliceostatin A and sudemycin D6/K exhibit improved stability and lower inhibitory $\mathrm{IC}_{50}$ concentrations, making them more suitable for therapy [293-295]. The bi-flavonoid Isoginkgetin also inhibits splicing by preventing U4, U5 and U6 tri-snRNP recruitment to the spliceosome [296]. Recently, several novel inhibitors of the pre-mRNA splicing helicase Brr2, which orchestrates spliceosome rearrangements during splicing events [297], have been identified are currently being characterized (Fig. 6b) [298, 299].

\section{RNA-based therapeutics for splice switching}

RNA-based therapeutics have the potential to target any mRNA and, therefore, any protein, including proteins that lack catalytic activity, cannot be targeted by small molecular inhibitors or that are unamenable to antibody targeting.

Antisense oligonucleotides (ASOs) are the mainstay of RNA-based therapeutics. ASOs are 15-39mer chemically-modified RNA or DNA molecules that either redirect specific splicing events to prevent pathologypromoting splice isoforms or to generate isoforms that inhibit pathology. The first proof of concept for therapeutic ASOs efficacy in preventing aberrant alternative splicing has come from the FDA-approved ASO "Spiranza", that targets survival motor neuron 2 (SMN2) premRNA to promote exon 7 inclusion and full length SMN2 protein expression and has been successfully employed to treat spinal muscular atrophy [300, 301]. Target-specific ASOs can also be used to switch splicing by targeting $3^{\prime}$ or $5^{\prime}$ splice sites blocking their use, or to promote exon or intron inclusion by targeting splicing enhancer or silencer sequences. Unmodified DNA and RNA oligonucleotides are unstable and vulnerable to nuclease attack. Therefore, therapeutic ASOs contain chemical modified phosphate or ribose backbones, increasing stability and specificity, whilst maintaining low toxicity and immunogenicity and can also be used to induce RNAse $\mathrm{H}$-mediated nonsense mediated mRNA decay. Common modifications include phospho-thioate linked backbones or 2' O-(2-methoxyl) or 2' O-methyl ribose modifications that increase half-lives from 2 weeks to 6 months, facilitating the use of shorter locked nucleic acid sequences with increased specificity and reduced off-target hybridizations. Phosphorodiamidate linkages in morpholino oligonucleotides further increases specificity and lowers toxicity but these ASOs must be conjugated with a delivery moiety for in vivo targeting [302]. Peptide nucleic acids ASOs are also highly specific, have been used to inhibit splicing events, are considerably more stable but exhibit lower solubility, limiting their use [303]. ASO delivery is also important and is achieved either systemically or by direct injection at site, with conjugation used to facilitate targeting (e.g. ASO conjugation with $\mathrm{N}$-acetylgalactosamine promotes uptake by hepatocytes). In vitro conjugated ASOs that promote exon 3 inclusion in STAT3 by shifting axon 3a inclusion to exon $3 \mathrm{~b}$, which lacks nucleotides encoding the carboxyl terminal transactivation domain, induce apoptosis and tumour regression in a murine breast cancer model and targeted ASOs that induce MDM4 exon 6 skipping and decrease MDM4 protein levels reduce tumour growth in patient-derived xenograft melanoma and lymphoma models and are currently under clinical evaluation (Fig. 6b [304].

\section{Chemotherapeutic agents that modify alternative splicing}

Camptothecin and topotecan topoisomerase inhibitors, doxorubicin and cisplatin have all been reported to induce splicing changes in genes involved in DNA damage-repair, genetic stability and immortality [305, 306]. Doxorubicin also induces alternative splicing of the NF-YA component of the heterotrimeric ubiquitous transcription factor NF-Y in human neuroblastoma cells, resulting in expression of a cytotoxic NF-YAx exon 3 and exon 5 skipped isoform that, upon overexpression, induces neuroblastoma cell autophagic necroptosis [92]. Combinations of cancer drugs with splicing modulators have also been shown to enhance therapeutic efficacy, e.g. amiloride potentiates imatinib efficacy in chronic myeloid leukemia [307, 308] and sudemycin enhances ibrutinib efficacy in chronic lymphocytic leukemia (Fig. 6b) [309].

\section{Targeting splicing factors}

Splicing factors are divided into the serine/arginine-containing SR proteins: SRSFs 1-12, SC35, SRp20, SRp30c, SRp38, SRp40, SRp54, SRp55, SRp75, HTra2 $\alpha$, HTra2 $\beta 1$, 9G8, SF2/ASF and SRm160; nhRNPs: hnRNPA0, A1, A2/B1, A3, C, C1, C2, D, D0, DL, E1, E2, F, G, H1, H2, I (PTB), J, K, L, LL, M, Q, U, nPTB; and others: RBFox-1, RBFox-2,, DAZAP1, PSF, TDP43, RBM4, RBM5, RBM 10, RBM25, CUG-BP1, ESRP1, ESRP2, ETR-3, HuB, HuC, HuD, HuR, TIA-1, TIAL1, QK1, Sam68, SLM-1, 
SLM-2, SF1, SRSF2, SRSF3B1, U2AF1, FMRP, Nova-1, Nova-2, PRPF40B, KSRP, ZRANB2, MBNL1, YB-1, SAP155 ZRSR2 [310]. Splicing factors bind cis-ESE, ESS, ISE and ISS elements and recruit or interact with proteins that interact with RNA recognition motifs involved in sequence-specific RNA binding interactions and mRNA transport. Small molecule inhibitors can interfer with tertiary RNA structures, protein/RNA binding interactions and SR splicing factor binding to cis enhancer or silencer elements in introns and exons (e.g Spiranza which binds SMN2 mRNA to promote exon 7 inclusion by inhibiting an ISS) [300, 301]. Furthermore, hnRNPs are essential for normal eukaryotic cell function, survival, tumourigenesis [311, 312] and are therefore important potential therapeutic targets.

The oral selective inhibitor of nuclear export KPT-330 (Selinexor) [313], impairs hnRNP K and A1 nuclearcytoplasmic shuttling in myelodysplastic syndrome and acute myeloid leukemia cells, providing a way to preferentially kill leukemia cells and exhibits encouraging anti-tumour activity in hematological and solid tumours $[313,314]$. The Quinilone derivative 1-(4-methoxyphenyl)3_(4-morpholino-6-nitroquinolin-2-yl)prop-2-en-1-one (compound 25) binds hnRNP K at micromolar concentrations, down-regulates c-Myc transcription and inhibits human cancer cell proliferation and human xenograft tumour growth in mice [315]. SiRNA knockdown of HnRNP A2/ B1, which regulates pre-mRNA processing, mRNA metabolism, transportation and is implicated in various cancers, including advanced stage human gliomas, induces apoptosis and Ros generation and reduces the viability, adhesion, migration, invasion, chemoresistance of glioma cell lines (U251 and SHG44), identifying HnRNP A2/B1 as a relevant therapeutic target in gliomas [316]. HnRNPB1 expression correlates with lung cancer development and siRNA HnRNPB1 knockdown promotes A549 lung cancer cell apoptosis [317], and several potential inhibitory small HnRNPB1 binding molecules have also recently been identified amongst lung cancer drugs [318]. In contrast to full length HnRNP L splicing factor, the HnRNP L alternative exon 7 splice variant, which contains a stop codon, promotes head and neck squamous cell carcinogenesis and is therefore a potential target, and SRSF3 splice factor is also autoregulated by an alternative exon 4 splice variant in a manner similar to hnRNP L, and is promoted by hnRNP L. HnRNP L is also overexpressed in liver, lung and prostate cancer and siRNA HnRNP L knockdown inhibits prostate cancer cell proliferation and xenograft tumour growth in mice, and hnRNP L overexpression interacts with p53, cyclin p21 and Bcl2, identifying hnRNP $\mathrm{L}$ inhibition as a potential therapeutic strategy in prostate cancer (Fig. 6a) [319].

The ubiquitin proteasome pathway inhibitor Bortezomib reduces the proliferation CA46 and Daudi Burkitt lymphoma cells by down regulating the expression of high molecular weight sumoylated hnRNP K splicing factor and cMyc and up-regulating the expression of low molecular weight de-sumoylated hnRNP $\mathrm{K}$, implicating sumoylated hnRNP K and cMyc repression in Bortezomib inhibition of Burkitt Lymphoma cell proliferation [320]. SiRNA hnRNPA1 knockdown inhibits HepG2 hepatocellular carcinoma cell proliferation, migration, promotes alternative PKM2 splicing and induces glycolysis, which influences glucose-dependent HnRNPA1 acetylation, de-acetylated under glucose starvation conditions by SIRT1 and SIRT6 sirtuins, which inhibit glycolysis by reducing PKM2 and increasing PMK1 expression, implicating an adaptive hnRNPA1 acetylation-regulated metabolic reprogramming mechanism for HCC metabolic adaptation, proliferation and tumourigenesis, within nutrient-deprived tumour microenvironments (Fig. 6a) [321].

\section{Targeting splice factor kinases}

Therapeutic targeting of splice factor kinases, which modulate splice factor involvement in spliceosome assembly, splice factor binding to splice sites and subsequently alternative splicing may also reduce the expression and activity of hypoxia-induced alternatively spliced tumour promoting protein isoforms [322]. Selective inhibitors of dual specificity CLK 1-4 splice factor kinases, activated by autocatalysis that phosphorylate SR proteins on serine/threonine residues to regulate alternative splicing, are being developed [322]. The small molecular nanomolar casein kinase-2 inhibitor CX-4945 inhibits CLKs1-4 and exhibits anti-proliferative, antiangiogenic and anti-tumour activity in mouse tumor xenograft models, inhibits PI3K/Akt signaling and HIF1 $\alpha$ transcription, and is currently in clinical trials for bile duct cholangiocarcinoma, with gemcetibine and cisplatin [323]. Other small molecule CLK inhibitors include TG003 and $\mathrm{KH}-\mathrm{CB} 19$ but their clinical potential in regulating splicing requires careful evaluation due to off-target side effects. The small molecule Wnt signaling pathway inhibitor SM08502 also inhibits CLKs (CLK3 and DRYKs) and oral SM08502 administration exhibits antitumor effects in mouse GI tumour xenograft models, inhibits SRSF phosphorylation, induces DVL2, TCFJ, ERBB2 and LRP5 alternative intron retention splicing and NMD, implicating alternative splicing in Wnt pathway signaling [324]. SM08508 inhibition of CLK2, CLK 3 and Wnt signaling is likely to disrupt spliceosomes, resulting in unstable alternative intron-retained splice transcripts, subsequently degraded by NMD. SM08508 also induces apoptosis regardless of the K-Ras or Wnt mutational status, permeates the nucleus and is in phase I clinical trials (NCT03355066) in patients with advanced stage solid tumours [324]. Amiloride, discovered 
in a screen of small molecule inhibitors of hepatocellular carcinoma Huh-7 cells, modulates oncogenic alternative splicing, devitalizes cancer cells, normalizes Bclx, HPK3 and RON/MISTR1 transcripts in association with SF2/ ASF hypo-phosphorylation, reduces the expression of SRp20 and 2 other SR proteins, decreases AKT, ERK1/2 and PP1 phosphorylation and increases p38 and JNK phosphorylation, in association with global changes in alternative splicing, involving 584 exons in 551 ion transport, cell matrix formation, cytoskeletal remodeling and genome maintenance gene transcripts, reducing cellular invasion and migration, cell cycle disruption, cytokinesis and inducing cell death. Similar effects were also observed in myeloid leukemia and glioblastoma cells, identifying Amiloride as a novel small molecule modulator of oncogenic alternative splicing of therapeutic relevance (Fig. 6b) [325].

\section{Targeting specific tumour promoting hypoxia-induced alternative spliced protein isoforms}

Targeted therapies for the hypoxia-induced alternatively spliced EGFRvIII driver oncogene, include 1st generation (Gefitinib, Erlotinib and Lapatinib), 2nd generation (Afatinib and Dacomitinib) and 3rd generation (Rociletinib and AZD9291) tyrosine kinase inhibitors; EGFR L2 domain targeting antibodies (Cetuximab, Panitumumab and Nimotuzumab), the EGFRvIII-specific antibody mAB806 or antibodies conjugated with a toxins or radioisotopes (125ImAB425) and the double specificity (bis) antibody bscEGFRvIIIxCD3. A vaccine against EGFRvIII (Rindopepimut CDX110), however, has failed in phase III trials. CAR-T cells that target EGFRvIII are another promising option and are in phase I clinical trials, and RNA-based anti-EGFRvIII therapeutics are being evaluated in animal models [326, 327]. Therapeutic strategies for the inhibition of the hypoxia-promoted TrkAIII oncogene, a potential driver oncogene in cancers including neuroblastoma and Merkel cell carcinoma, include the small molecule Trk tyrosine kinase inhibitors, Larotrectinib, Entrectinib, Cabozantinib, Merestinib, TRS-011, DS-6051B, MGCD156, PLX486 and DCC-2710, FDA-approved or in clinical trials for cancers with Trk-fusion oncogenes or with altered Trk activity, that could be repurposed for treating tumours that express TrkAIII (Fig. 6b) [328]. Alternative approaches include TrkAIII-specific PNA inhibitors or equivalent siRNAs to repress TrkAIII expression, geldanamycin analogues, SOD-2 inhibitors, TRAIL or agents that target TrkAIII downstream signaling, such as PI3K/ Akt/NF-kB inhibitors, the UPR, Bcl2, Bcl-xL and Mcl-1 proteins [90]. Recently, a novel humanized anti-RON antibody-drug conjugate Zt/g4-MMAE has been developed and validated for evaluation in the treatment of pancreatic cancer (Fig. 6b) [329]. Alternative approaches include: vaccination against tumour-specific splice variants with splice variant antigenic epitopes conjugated to keyhole limpet hemocyanin [330], the generation of CAR-T cells that target tumour-specific splice isoform [331] and the use of RNA and DNA ASOs, PNA, RNAi, ribozymes and adjuvant microRNA based strategies to reduce splice variant expression (see above).

\section{Conclusions}

It is clear that tumour hypoxia-induced alternative splicing plays a fundamental role in all 10 cancer hallmarks, from initiation to metastatic growth, and is also a critical determinant of therapeutic resistance. The influence of hypoxia upon the basic mechanisms of pre-mRNA splicing including spliceosome assembly, splicing factor expression, activity and intracellular localization, miRNA synthesis and maturation, and the added influence of mRNA structure and elongation rate, results in an impressive number of alternatively spliced protein isoforms that promote tumor pathogenesis, metastatic progression and therapeutic resistance, warranting classification of hypoxia-induced alternative splicing as the 11th hallmark of cancer. Tumour hypoxia-induced alternative splicing provides a plethora of biomarkers of prognostic potential and therapeutic targets with potential to slow tumour progression and enhance therapeutic efficacy.

\section{Abbreviations}

HIF: Hypoxia-inducible factor; CREB: CAMP response element binding protein: STAT-3: Signal transducer and activator of transcription-3; VEGF: Vascular endothelila cell growth factor; VEGFR: Vascular endothelial cell growth factor receptor; TrkA: Tropomyosin-related kinase receptor A; EGFR: Epithelila growth factor receptor; TGF: Transforming growth factor; MARS: Methionine tRNA synthetase; CLK: CDC-like kinase; STPK: Serine/threonine protein kinase; MALAT: Metastasis-associated lung adenocarcinoma transcript; LUCAT: Lung cancer associated transcript; HOTAIR: HOT transcript antisense RNA;

TNF: Tumour necrosis factor; Bcl: B-cell lymphoma; PI3K: Phosphoinositol-3kinase; CK: Casein kinase; GW: Gawky bodies; PB: Processing bodies; NFY: Nuclear factor-Y; PTP: Protein tyrosine phosphatase; RON: Recepteur d'Origine Nantais kinase; MAPK: Mitogen-activated kinase; XBP: X-box-binding protein; AP-1: Activator protein-1; NF-kB: Nuclear factor kappa binding; mTOR: Mechanistic target of rapamycin kinase; ATR: Ataxia telangectasia and RAD3-related protein; BRCA: Breast cancer gene; BAX: Bcl-2 associated X; HDAC: Histone deacetylase; TP53BP1: Tumour protein p53 binding protein-1; TP53: Tumour promoting protein 53; Waf-1: Wild-type p53 activated protein; PTBP1: Polypyrimidine tract-binding protein-1; TERT: Telomerase reverse transcriptase; PHD: Hif prolyl hydroxylase; PDHC: Pyruvate dehydrogenase complex; PK: Pyruvate kinase; ARNT: Aryl hydrocarbon receptor nuclear translocator; EMMPRIN: Extracellular matrix metalloproteinase inducer; MiRNA: Micro RNA; EGFL: Epithelial growth factor-like; PGC-1a: Peroxisome proliferator-activated receptor coactivator 1-alpha; sVEGFR: Soluble vascular endothelila cell growth factor receptor; NK: Natural killer; TRAIL: TNF-related apoptosis inducing ligand; BNIP3: BCl2/adenovirus E1B protein interacting protein-3; PERK: Pancreatic E1F2-alpha kinase; ER: Endoplasmic reticulum; UPR: Unfolded protein response; RIPK: Receptor-interacting serine/threonine kinase; HLA: Human leukocyte antigen; PD-1: Programmed death - 1; PDL1: Programmed death-ligand 1; TDP-43: Tar DNA binding protein; MCP: Membrane cofactor protein; LDHA: Lactate dehydrogenase A; NMD: Nonsense-mediated RNA decay; EMT: Epithelila to mesenchymal transition; ZEB: Zinc finger E-box-binding homeobox; MFAP: Microfibrillarassociated protein; PTK: Protein tyrosine kinase; TRPM2: Transient receptor potential cation channel subfamily M member 2; GA: Geldanamycin; 17DMAG: 17-dimethylaminoethylamino-17-demethoxygeldanamycin; 
snRNP: Small nuclear ribonucleoprotein; hnRNP: Heterogeneous nuclear ribonucleoprotein; ASO: Antisense oligonucleotide; SMA: Spinal muscular atrophy; MDM4: Mouse double minute; Wnt-1: Wingless and Int-1; HPK: Homeodomain-interacting protein kinase; CAR-T: Chimeric antigen receptor-T; PNA: Peptide nucleic acid; siRNA: Small interfering RNA.

\section{Acknowledgments}

Not applicable.

\section{Authors' contributions}

All authors made substantial contributions to articles reviewed in this manuscript, were involved in the drafting and revision, and approved the final version of this manuscript.

\section{Funding}

This article was funded by the Maugeri Foundation.

\section{Availability of data and materials}

Data supporting the conclusions of this article and all other data concerning reviewed articles, for which data was obtained at the University of L'Aquila are available from the authors upon reasonable request.

\section{Ethics approval and consent to participate}

Manuscripts reviewed in this article, for which data was obtained at the University of L'Aquila, all received approval from the University of L'Aquila ethical committee.

\section{Consent for publication}

Not applicable.

\section{Competing interests}

The authors declare that they have no competing interests.

Received: 19 May 2020 Accepted: 3 June 2020

Published online: 15 June 2020

\section{References}

1. Warburg O. On respiratory impairment in cancer cells. Science. 1956;1 (24): 269-70.

2. Vander Heiden MG, Cantley LC, Thompson CB. Understanding the Warburg effect: the metabolic requirements of cell proliferation. Science. 2009;324: 1029-33.

3. Al Tameemi W, Dale TP, Al-Jumaily RMK, Forsyth NR. Hypoxia-modified Cancer cell metabolism. Front Cell Dev Biol. 7:4. https://doi.org/10.3389/fcell. 2019.00004

4. Romero-Ramirez L, Cao H, Nelson D, Hammond E, Lee A-H, Yoshida H, et al XBP1 is essential for survival under hypoxic conditions and is required for tumor growth. Cancer Res. 2004:64:5943-7.

5. Daskalaki I, Gkikas I, Tavernarakis N. Hypoxia and selective autophagy in cancer development and therapy. Front Cell Dev Biol. 2018;6:104. https:// doi.org/10.3389/cell.2018.00104

6. Vaupel P, Harrison L. Tumor hypoxia: Causative factors, compensatory mechanisms, and cellular response. Oncologist. 2004;9:4-9.

7. Petrova V, Annicchiarico-Petruzzelli M, Melino G, Amelio I. The hypoxic tumour microenvironment. Oncogenesis. 2018;7:10. https://doi.org/10.1038/ s41389-017-0011-9

8. Qu J, Guo X, Li W, Hou W, Zhang H, Luo L, et al. Preparation of artificial red cell and its alleviation of tumor hypoxia. Colloids Surf B Biointerfaces. 2017; 160:446-54.

9. Gilkes DM, Semenza GL, Wirtz D. Hypoxia and the extracellular matrix: drivers of tumor metastasis. Nat Rev Cancer. 2014;14:430-9.

10. Spill F, Reynolds DS, Kamm RD, Zaman MH. Impact of the physical microenvironment on tumor progression and metastasis. Curr Opin Biotechnol. 2016:40:41-8.

11. Harada H. How can we overcome tumor hypoxia in radiation therapy? Radiat Res. 2011:52:545-56.

12. Gort EH, Groot AJ, van der Wall E, van Diest PJ, Vooijs MA. Hypoxia regulation of metastasis via hypoxia-inducible factors. Curr Mol Med. 2008;8:60-7

13. Philip B, Ito K, Moreno-Sànchez R, Ralph SJ. HIF expression and the role of hypoxic environments within primary tumours as protective sites driving cancer stem cell renewal and metastatic progression. Carcinogenesis. 2013; 34:1699-707.

14. Qui G-Z, Jin M-Z, Dai J-X, Sun W, Feng J-H, Jin WL. Reprogramming of the tumor in the hypoxic niche: The emerging concept and associated therapeutic strategies. Trends in Pharmacol Sci. 2017;38:669-86.

15. Hockel M, Schlenger K, Aral B, Mitze M, Schaffer U, Vaupel P. Association between tumor hypoxia and malignant progression in advanced cancer of the uterine cervix. Cancer Res. 1996:56:4509-15.

16. Monteiro AR, Hill R, Pilkington GJ, Madureira PA. The role of hypoxia in glioblastoma invasion. Cells. 2017;6:45. https://doi.org/10.3390/cells6040045.

17. Spector DL, Lamond Al. Nuclear Speckles. Cold Spring Harb Perspect Biol. 2011;3:a000646. https://doi.org/10.1101/cshperpect.a000646.

18. Schmucker D, Clemens JC, Shu H, Worby CA, Xiao J, Muda M, et al. Drosphila Dscam is an axon guidance receptor exhibiting extraordinary molecular diversity. Cell. 2000;101:671-84.

19. Keleman O, Convertini $P$, Zhang Z, Wen Y, Shen M, Falaleeva M, et al. Function of alternative splicing. Gene. 2013;514:1-30.

20. Gallego-Paez LM, Bordone MC, Leote AC, Saraiva-Agostinho N, AscensaoFerreira M, Barbosa-Morais NL. Alternative splicing: the pledge, the turn, and the prestige: the key role of alternative splicing in human biological systems. Hum Genet. 2017;136:1015-42.

21. Sperling R. Small non-coding RNA within the endogenous spliceosome and alternative splicing regulation. BBA Gene Reg Mech. 2019;1862:194406. https://doi.org/10.1016/j.bbagrm.2019.07.007.

22. Clancy S. RNA splicing, introns, exons and spliceosome. Nat Edu. 2008;1:31.

23. Matera AG, Wang Z. A day in the life of a spliceosome. Nat Rev Mol Cell Biol. 2014;15:108-21.

24. Berget SM. Exon recognition in vertebrate splicing. J Biol Chem. 1995;270: 2411-4.

25. Shenasa $\mathrm{H}$, Hertel $\mathrm{KJ}$. Combinatorial regulation of alternative splicing. BBA Gene Reg Mech. 2019;1862:194392. https://doi.org/10.1016/j.bbagrm.2019. 06.003 .

26. Galbraith MD, Allen MA, Bensard CL, Wang X, Schwinn MK, Qin B, et al. HIF1A employs CDK8-mediatro to stimulate RNAPII elongation in response to hypoxia. Cell. 2013;153:1327-39.

27. Brzyzek G, Sweizewski S. Mutual interdependence of splicing and transcription. Transcription. 2015;6. https://doi.org/10.1080/21541264.2015. 1040146.

28. Fox-Walsh KL, Dou Y, Lam BJ, S-p H, Baldi PF, Hertel KJ. The architecture of pre-mRNAs affects mechanisms and splice-site pairing. Proc Natl Acad Sci USA. 2005;102:16176-81.

29. Bell MV, Cowper AE, Lefranc M-P, Bell JI, Screaton GR. Influence of intron length on alternative splicing of CD44. Mol Cell Biol. 1998;18:5930-41.

30. Rueter SM, Dawson TR, Emeson RB. Regulation of alternative splicing by RNA editing. Nature. 1999:399:75-80.

31. Gonzales C, Almarez L, Obeso A, Rigual R. Carotid body chemoreceptors: from natural stimuli to sensory discharges. Physiol Rev. 1994;74:829-98.

32. McCartney CE, McClafferty H, Huibant J-M, Rowan EG, Shipston MJ, Rowe CM. A cysteine-rich motif confers hypoxia sensitivity to mammalian large conductance voltage- and Ca-activated K (BK) channel a-subunits. Proc Natl Acad Sci USA. 2005:102:17870-5.

33. Smith TG, Robbins PA, Ratcliffe PJ. The human side of hypoxia-inducible factor. Br J Haematol. 2008:141:325-34.

34. Chang S-H, Elemento O, Zhang J, Zhuang ZW, Simons M, Hla T. ELAVL1 regulates alternative splicing of elF4E transporter to promote postnatal angiogenesis. Proc Natl Acad Sci USA. 2014;111:18309-14.

35. Brady LK, Wang $H$, Radens CM, Bi Y, Radovich M, Maity A, et al. Transcriptome analysis of hypoxic cancer cells uncovers intron retention in E1F2B5 as a mechanism to inhibit translation. PLOS Biol. 2017:15: e2002623.

36. Sena JA, Wang L, Heasley LE, Hu C-J. Hypoxia regulates alternative splicing of HIF and non-HIF target genes. Mol Cancer Res. 2014;12:1233-43.

37. Maxwell PH, Wiesener MS, Chang GW, Clifford SC, Vaux EC, Cockman ME, et al. The tumour suppressor protein $\mathrm{VHL}$ targets hypoxia-inducible factors for oxygen-dependent proteolysis. Nature. 1999:399:271-5.

38. Ivan M, Kondo K, Yang H, Kim W, Valiando J, Ohh M, et al. HIFalpha targeted for VHL-mediated destruction by proline hydroxylation: implications for $\mathrm{O} 2$ sensing. Science. 2001:292:464-8.

39. Jaakkola P, Mole DR, Tian YM, Wilson MI, Gielbert J, Gaskell MJ, et al. Targeting HIF-alpha to the von Hippel-Lindau ubiquitinylation complex by O2-reguilated Prolyl hydroxylation. Science. 2001;292:468-72. 
40. Ohh M, Park CW, Ivan M, Hoffman MA, Kim TY, Huang LE, et al. Ubiquitination of hypoxia-inducible factor requires direct binding to the beta-domain of the von Hippel-Landau protein. Nature Cell Biol. 2000;2:423-7.

41. Nakayama K, Kataoka N. Regulation of gene expression under hypoxic conditions. Int J Mol Sci. 2019;20:3278. https://doi.org/10.3390/ijms20133278.

42. Liu W, Shen SM, Zhao XY, Chen GQ. Targeted genes and interacting proteins of hypoxia inducible factor-1. Int J Biochem Mol Biol. 2012;3:165-78.

43. Kanopka A. Cell survival: interplay between hypoxia and mRNA splicing. Exp Cell Res. 2017;356:187-91.

44. Leung SK, Ohh M. Playing tag with HIF: the VHL story. J. Biomed Biotechnol. 2002:2:131-5

45. Han HJ, Kwon N, Choi MA, Jung KO, Ngo HK, Kim SJ, et al. Peptidyl prolyl isomerase 1 PIN1 directly binds to and stabilizes hypoxia-inducible factor 1a. PLOS ONE. 2016;11:e014038.

46. Choi Y-J, Kim I, Lee JE, Park J-W. PIN1 transcript variant 2 acts as a long noncoding RNA that controls the HIF-1-driven hypoxic response. Sci Rep. 2019; 9:10599 https://doi.org/10.1038/s41598-019-47071-1.

47. Oliver KM, Taylor CT, Cummins EP. Hypoxia. Regulation of NFkappaB signaling during inflammation: the role of hydroxylases. Arthritis Res Ther. 2009;11:215. https://doi.org/10.1186/ar2575.

48. Siddiq A, Aminova LR, Ratan RR. Prolyl-hydroxylase activity-responsive transcription factors: from hydroxylation to gene expression and neuroprotection. Front Biosci. 2008;13:2875-87.

49. Gaisina IN, Lee SH, Kaidery NA, Ben Aissa M, Ahuja M, Smirnova MM, et al. Activation of $\mathrm{Nrf} 2$ and hypoxic adaptive response contribute to neuroprotection elicited by phenylhydroxamic acid selective HDAC inhibitors. ACS Chem Neurosci. 2018;9:894-900.

50. Gerber SA, Yatsula B, Maier CL, Sadler TJ, Whittaker LW, Pober JS. Interferongamma induces prolyl hydroxylase (PHD)3 through STAT1-dependent mechanism in human endothelial cells. Arterioscler Thromb Vasc Biol. 2009; 29:1363-9.

51. Bowler E, Oltean S. Alternative splicing in angiogenesis. Int J Mol Sci. 2019; 20:2067. https://doi.org/10.3390/ijms20092067.

52. Gothié E, Richard DE, Berra E, Pagès G, Pouysségur J. Identification of alternative spliced variants of human hypoxia-inducible factor 1a. J Biol Chem. 2000;275:6922-7.

53. Duan C. Hypoxia-inducible factor 3 biology: complexities and emerging themes. Am J Cell Physiol. 2016;310:C260-9.

54. Hang X, Li P, Li Z, Qu W, Yu Y, Li H, et al. Transcription and splicing regulation in human umbilical vein endothelial cells under hypoxic stress conditions by exon array. BMC Genomics. 2009;126. https://doi.org/10.1186/ 1471-2164-10-126.

55. Jiminez M, Arechederra M, Avila MA, Berasain C. Splicing alterations contributing to cancer hallmarks in the liver: central control of dedifferentiation and genome instability. Transl Gastroenterol Hepatol. 2018; 3:84. https://doi.org/10.21037/tgh.2018.10.11.

56. Han J, Li J, Ho JC, Chia GS, Kato H, Jha S, et al. Hypoxia is a key driver of alternative splicing in human breast cancer cells. Sci Rep. 2017;7:4108. https://doi.org/10.1038/s41598-017-04333-0.

57. Brady LK. Transcriptome-wide analysis of hypoxic cancer cells identify alternative splicing as a mechanism to inhibit translation. 2017; Publicly Accessible Penn Dissertations. 2196. https://repository.upenn.edu/ edissertations/2196.

58. Lorenzini PA, Chew RSE, Tan CW, Yong JY, Zhang F, Roca X. Human PRPF $40 B$ regulates hundreds of alternative splicing targets and represses a hypoxia expression signature. RNA. 2019;25:905-20.

59. Jakubauskiene E, Vilys L, Makino Y, Poellinger $L$, Kanopka A. Increased serinearginine (SR) protein phosphorylation changes pre-mRNA splicing in hypoxia. J Biol Chem. 2015;290:18079-89.

60. Goncalves $V$, Jordan P. Posttranscriptional regulation of splicing factor SRSF1 and its role in cancer cell biology. Biomed Res Int. 2015. https://doi.org/10. $1155 / 2015 / 287048$.

61. Uniacke J, Holterman CE, Lachance G, Franovic A, Jacob MD, Fabien MR, et al. An oxygen-regulated switch in the protein synthesis machinery. Nature. 2012;486:126-9.

62. Wang Y, Cheen D, Qian H, Tsai YS, Shao S, Liu Q, et al. The splicing factor RBM4 controls apoptosis, proliferation, and migration to suppress tumor progression. Cancer Cell. 2014;26:374-89.

63. Chen T-M, Lai M-C, Li Y-H, Chan Y-L, Wu C-H, Wang Y-M, et al. hnRNPM induces translation switch under hypoxia to promote colon cancer development. EBioMed. 2019;41:299-309.
64. Hirschfeld M, Hausen AZ, Bettendorf $H$, Jager M, Stickeler E. Alternative splicing of Cry61 is regulated by hypoxia and significantly changed in breast cancer. Cancer Res. 2009;69:2082-90.

65. Amirkhah R, Naderi-Meshkin H, Shah JS, Dunne PD, Schmitz U. The intricate interplay between epigenetic events, alternative splicing and noncoding RNA deregulation in colorectal cancer. Cells. 2019;8:929. https://doi.org/10. 3390/cells8080929.

66. Dhamija S, Diederichs S. From junk to master regulators of invasion: IncRNA functions in migration, EMT and metastasis. Int J Cancer. 2016;139:269-80.

67. Xu C, Yang M, Tian J, Wang X, Li Z. MALAT-1: a long non-coding RNA and its important 3' end functional motif in colorectal cancer metastasis. Int J Oncol. 2011;39:169-75.

68. Shih J-W, Kung H-J. Long non-coding RNA and tumor-hypoxia: new players ushered toward an old arena. J Biomed Sci. 2017;24:53. https://doi.org/10. 1186/s12929-017-0358-4.

69. Cho H-S, Han T-S, Hur K, Ban HS. The roles of hypoxia-inducible factors and non-coding RNAs in gastrointestinal cancer. Genes. 2019;10:1008. https://doi org/10.3390/genes10121008.

70. Xiao H, Tang K, Liu P, Chen K, Hu J, Zeng J, et al. LncRNA MALAT1 functions as a competing endogenous RNA to regulate ZEB2 expression by sponging miR-200s in clear cell kidney carcinoma. Oncotarget. 2015;6:38005-15.

71. Hu L, Tang J, Huang X, Zhang T, Feng X. Hypoxia exposure upregulates MALAT-1 and regulates the transcriptional activity of PTB-associated splicing factor in A549 lung adenocarcinoma cells. Oncol Letters. 2018;16:294-300.

72. Yang J, Kim WJ, Jun HO, Lee EJ, Lee KW, Jeong JY, et al. Hypoxia-induced fibroblast growth factor 11 stimulates capillary-like endothelial tube formation. Oncol Rep. 2015;34:2745-51.

73. Yin J, Lee JH, Gao JZ, Polotsky VY, Ye J. Regulation of hepatocyte growth factor expression by NF-kB and PPARY in adipose tissue. Am J Endocrinol Metabol. 2014;306:E929-36.

74. Jiang Y, Dai $A$, Li Q, Hu R. Hypoxia induces transforming growth factor- $\beta 1$ gene expression in the pulmonary artery of rats via hypoxia-inducible factor-1a. Acta Biochim Biophys Sin. 2007;39:73-80.

75. Mishra OP, Ashraf QM, Delivoria-Papadopoulos M. Hypoxia-induced activation of epidermal growth factor receptor (EGFR) kinase in the cerebral cortex of newborn piglets: the role of nitric oxide. Neurochem Res. 2010;35: 1471-7.

76. Ren H, Accili D, Duan C. Hypoxia converts the myogenic action of insulinlike growth factors into mitogenic action by differentially regulating multiple signaling pathways. Proc Natl Acad Sci USA. 2010;107:5857-62.

77. Chen C, ZXhao S, Karnad A, Freeman JW. The biology and role of CD44 in cancer progression: therapeutic implications. J Hepatol Oncol. 2018;11:64. https://doi.org/10.1186/s13045-018-0605-5.

78. Goncalves V, Pereira JFS, Jordan P. Signaling pathways driving aberrant splicing in cancer cells. Genes. 2018;9:9. https://doi.org/10.3390/ genes9010009.

79. Macharia LW, Wanjiru CM, Mureithi MW, Pereira CM, Ferrer VP, Moura-Neto V. MicroRNAs, hypoxia and the stem-like state as contributors to cancer aggressiveness. Front Genet. 2019;10:125. https:/doi.org/10.3389/gene.2019.00125.

80. Andersen P, Kedersha N, Ivanov P. Stress granules. P-bodies and cancer. Biochem Biophys Acta. 1849;2015:861-70.

81. Kucherenko MM, Shcherbata HR. miRNA targeting and alternative splicing in the stress response-events hosted by membrane compartments. J Cell Sci. 2018;131:jcs 202002. https://doi.org/10.1242/jcs.202002.

82. Mahboubi H, Stochaj U. Cytoplasmic stress granules: dynamics modulators of cell signaling and disease. Biochim Biophys Acta Mol Basis Dis. 1863;2017: 884-95.

83. Ho DJJ, Metcalf JL, Yan MS, Turgeon PJ, Wang JJ, Chalsev M, et al. Functional importance of dicer protein in the adaptive cellular response to hypoxia. J Biol Chem. 2012;287:29003-20.

84. Kawahara Y, Miedo-Sato A. TDP-43 promotes microRNA biogenesis as a complex component of the drosha and dicer complexes. Proc Natl Acad Sci USA. 2012;109:3347-52.

85. Nallamshetty S, Chan SY, Loscalzo J. Hypoxia: a master regulator of MicroRNA biogenesis and activity. Free Radical Biol Med. 2013;64:20-30.

86. Bonomi S, Gallo S, Catillo M, Pignataro D, Biamonti G, Ghigna C. Oncogenic alternative splicing switches: Role in cancer progression and prospects for therapy. Int J Cell Biol. 2013. https://doi.org/10.1155/2013/962038.

87. Abou-faycal C, Hatat A-S, Gazzeri S, Eymin B. Splice variants of the RTK family: Their role in tumor progression and response to targeted therapy. Int J Mol Sci. 2017;18:383. https://doi.org/10.3390/ijms18020383. 
88. Gong Y, Dong Y, Cui J, Sun Q, Zhen Z, Gao Y, et al. Receptor tyrosine kinase interaction with the tumor microenvironment in malignant progression of human glioblastoma. In Gioma - Contemporary Diagnostic and Therapeutic Approaches Intech Open; 2019. https://doi.org/10.5772/intechopen.76873.

89. Tacconelli A, Farina AR, Cappabianca L, Desantis G, Tessitore A, Vetuschi et al. TrkA alternative splicing: a regulated tumor-promoting switch in human neuroblastoma. Cancer Cell 2004; 6:347-360.

90. Farina AR, Cappabianca L, Ruggeri P, Gneo L, Pellegrini C, Fargnoli MC, et al. The oncogenic neurotrophin receptor tropomyosin-related kinase variant. TrkAlll. J Exp Clin Canc Res. 2018;37:119. https://doi.org/10.1186/s13046.

91. Cappabianca L, Guadagni S, Maccarone R, Sebastiano M, Chiominto A Farina AR, et al. A pilot study of alternative splicing in Merkel cell carcinoma: a potential oncogenic mechanism and novel therapeutic target. J Exp Clin Cancer Res. 2019;38:424. https://doi.org/10.1186/s13046-019-1425-3.

92. Cappabianca L, Farina AR, Di Marcotullio L, Infante $P$, De Simone D, Sebastiano $M$, et al. Discovery, characterization and potential roles of a novel NF-YAx splice variant in human neuroblastoma. J Exp Clin Cancer Res. 2019;38:482. https://doi.org/10.1186/s13046-019-8.

93. Liu Z, Han L, Dong Y, Tan Y, Li Y, Zhao M, et al. EGFRvIll/integrin B3 interaction in hypoxic and vitronectin-enriching microenvironment promote GBM progression and metastasis. Oncotarget. 2015;7:4680-94.

94. Gu G, Gong K, Wohlfeld B, Hatanpaa KJ, Zhao D, Habib AA. Ligandindependent EGFR signaling. Cancer Res. 2015;75:3436-41.

95. Furnari FB, Cloughesy TF, Cavenee WK, Mischel PS. Heterogeneity of epidermal growth factor receptor signaling networks in glioblastoma. Nat Rev Cancer. 2015;15:302-10.

96. Paatero I, Seagroves TN, Vaparanta K, Han W, Jones FE, Johnson RS, et al. Hypoxia-inducible factor-1a induces Erb4 signaling in the differentiating mammary gland. J Biol Chem. 2014;289:22459-69.

97. Chen W-C, To MD, Westcott PMK, Delrosario R, Kim IJ, Philips M, et al. Regulation of KRAS4A/B splicing in cancer stem cells by the RBM39 splicing complex. BioRxiv. 2019. https://doi.org/10.1101/646125.

98. Nussinov R, Tsai C-J, Jang H. Oncogenic Ras isoforms signaling specificity at the membrane. Cancer Res. 2017;78:593-602.

99. Bowler E, Poranzinski S, Uzor S, Thibault P, Durand M, Lappinte E, et al. Hypoxia leads to significant changes in alternative splicing and elevated expression of CLK splice factor kinases in PC3 prostate cancer cells. BMC Cancer. 2018;18:355. https://doi.org/10.1186/s12885-018-4227-7.

100. Huan L, Guo T, Wu Y, Xu L, Huang S, Xu Y, et al. Hypoxia induced LUCAT1/ PTBP1 axis modulates cancer cell viability and chemotherapy response. Mol Cancer. 2020;19:11. https://doi.org/10.1186/s12943-1122-z..

101. Lim S, Yoo BK, Kim H-S, Gilmore HL, Lee Y, Lee HP, et al. Amyloid-b precursor protein promotes cell proliferation and motility of advanced breast cancer. BMC Cancer. 2014;14:928. https://doi.org/10.1186/1471-240714-928.

102. Nowak DG, Woolard J, Amin EM, Konopatskaya O, Saleem MA, Churchill AJ, et al. Expression of pro- and anti-angiogenic isoforms of VEGF is differentially regulated by splicing and growth factors. J Cell Sci. 2008;121:3487-95.

103. Boudria A, Faycal C, Jia T, Gout S, Keramidas M, Didier C, et al. VEGF 165b, a splice variant of VEGF-A, promotes lung tumor progression and escape from anti-angiogenic therapies through a $\beta 1$ integrin/NEGFR autocrine loop. Oncogene. 2018;38:1050-66.

104. Ramchandani D, Unruh D, Lewis CS, Bogdanov VY, Weber GF. Activation of carbonic anhydrase IX by alternatively spliced tissue factor under late-stage tumor conditions. Lab Invest. 2016:96:1234-45.

105. Thangasamy A, Rogge J, Ammanamanchi S. Receptuer d'origine Nantais Tyrosine kinase is a direct target of hypoxia-inducible factor-1a-mediated invasion of breast carcinoma cells. J Biol Chem. 2009;284:14001-10.

106. Chang H-Y, Liu H-S, Lai M-D, Tsai Y-S, Tzai T-S, Cheng H-L, et al. Hypoxia promotes nuclear translocation and transcriptional function in the oncogenic tyrosine kinase RON. Cancer Res. 2014;74:4549-62.

107. Zhou D, Huang L, Zhou Y, Wei T, Yang L, Li C. RON and RON $\Delta 160$ promote gastric cancer cell proliferation, migration, and adaptation to hypoxia via interaction with $\beta$-catenin. Aging. 2019;11:2735-48.

108. Krishnaswamy S, Mohammed AK, Amer OE, Tripathi G, Alokail MS, Al-Daghri NM. Recepteur d'Origine nantais (RON) tyrosine kinase splicing variants lacking exons 18 and 19 occur ubiquitously in lung cancer. Int J Clin Exp Med. 2015;8:20778-86.

109. Wang M-H, Padhye S, Guin S, Zhou Y-Q. Potential therapeutics specific to C$\mathrm{MET} / \mathrm{RON}$ receptor tyrosine kinases for molecular targeting in cancer therapy. Acta Pharmacol Sin. 2010;31:1181-8.
110. Zhang Y, Kaplan-Lefko PJ, Rex K, Yang Y, Moriguchi J, Osgood T, et al. Identification of a novel recepteur d'Origine nantais/c-Met small molecule kinase inhibitor with antitumor activity in vivo. Cancer Res. 2008;68:6680-7.

111. Ma Q, Zhang K, Guin S, Zhou Y-Q, Wang M-H. Deletion or insertion in the first immunoglobulin-plexin-transcription (IPT) domain differentially regulates expression and tumorigenic activities of RON receptor tyrosine kinase. N Mol Cancer. 2010;9:307.

112. Vandewynckel Y-P, Laukens D, Geerst A, Bogaerts E, Paredaens A, Verhelst X, et al. The paradox of the unfolded protein response in cancer. Anticancer Res. 2013;33:4683-94.

113. Chipurupalli S, Kannan E, Tergaonkar V, D’Andrea R, Robinson N. Hypoxia induces ER stress response as an adaptive mechanism in cancer. Int J Mol Sci. 2019;20:749. https://doi.org/10.3390/ijms20030749.

114. Xia Z, Wu S, Wei X, Liao Y, Yi P, Liu Y, et al. Hypoxic ER stress suppresses $\beta$ catenin expression and promotes cooperation between the transcription factors XBP1 and HIF1a for cell survival. J Biol Chem. 2019;294:13811-21.

115. Shi W, Chen Z, Li L, Liu H, Zhang R, Cheng Q, et al. Unravel the molecular mechanism of XBP1 in regulating the biology of cancer cells. J Cancer. 2019;10:2035-46.

116. Fang $P$, Xiang $L$, Huang $S$, Jin $L$, Zhou G, Zhuge L, et al. IRE1a-XBP1 signaling pathway regulates IL-6 expression and promotes progression of hepatocellular carcinoma. Oncol Letters. 2018;16:4729-36.

117. Wang H-L, Wu C-F, Rajasekaran N, Shin YK. Loss of tumor suppressor gene function in human cancer: An overview. Cell Physiol Biochem. 2018;51: 2647-39.

118. Memon D, Dawson K, Smowton CSF, Wong W, Dive C, Miller CJ. Hypoxiadriven splicing into noncoding isoforms regulates DNA damage response. Npj Genomic Med. 2016;1:16020. https://doi.org/10.1038/npjgenmed.2016.20.

119. Robertson DM, Ho S-I, Cavanagh DH. Characterization of DNp63 isoforms in normal cornea and telomerase-immortalized human corneal epithelial cells. Exp Eye Res. 2008;86:576-85.

120. D’Aguanno S, Barcaroli D, Rossi C, Zucchelli M, Ciavardelli D, Cortese C, et al. p63 isoforms regulate metabolism of cancer stem cells. J Proteome Res. 2014;13:2120-36.

121. Pflaum J, Schlosser S, Muller M. p53 family and cellular stress response in cancer. Front Oncol. 2014;4:285. https://doi.org/10.3389/fonc.2014.00285.

122. Galban S, Kuwano Y, Pullman R Jr, Martindale $J$, Kim HH, Lal A, et al. RNA binding proteins HuR and PTB promote the translation of hypoxia-inducible factor 1a. Mol Cell Biol. 2008;28:93-107.

123. Bielle P, Panzeri V, Lattanzio R, Mutascio S, Pieraccioli M, Volpe E, et al. The splicing factor PTBP1 promotes expression of oncogenic splice variants and predicts poor prognosis in patients with non-muscle-invasive bladder cancer. Clin Cancer Res. 2018:24:5422-32.

124. Bernal A, Tusell L. Telomers: Implications for cancer development. Int J Mol Sci. 2018;19:294. https://doi.org/10.3390/ijms19010294.

125. Bojesen SE, Pooley KA, Johnatty SE, Beesley J, Mlchailidou K, Tyrer JP, et al. Multiple independent variants at the TERT locus are associated with telomer length and risks of breast and ovarian cancer. Nat Genet. 2013;45:371-84.

126. Teichroeb JH, Kim J, Betts $\mathrm{DH}$. The role of telomers and telomerase reverse transcriptase isoforms in pluripotency induction and maintenance. RNA Biol. 2016;18:707-19.

127. Radan L, Hughes CS, Teichroeb JH, Vieira Zamora FM, Jewer M, Postovit LM, et al. Microenvironmental regulation of telomerase isoforms in human embryonic stem cells. Stem cells Dev. 2014;23:2046-66.

128. Jie M-M, Chang X, Zeng S, Liu C, Liao GB, Wu WR, et al. Diverse regulatory manners of human telomerase reverse transcriptase. Cell Commun Signal. 2019;17:63. https://doi.org/10.1186/s12964-019-0372-0.

129. Anderson CJ, Hoare SF, Ashcroft M, Bilsland AE, Keith WN. Hypoxic regulation of telomerase gene expression by transcriptional and posttranscriptional mechanisms. Oncogene. 2006;25:61-9.

130. Zaffaroni N, Della Porta C, Villa R, Botti C, Buglioni S, Mottolese M, et al. Transcription and alternative splicing of telomerase reverse transcriptase in benign and malignant breast tumours and in adjacent mammary glandular tissues: implications for telomerase activity. J Pathol. 2002;198:37-46.

131. Zuazo-Gaztelu I, Cassanovas O. Unraveling the role of angiogenesis in cancer ecosystems. Front Oncol. 2018:8:248. https://doi.org/10.3389/fonc. 2018.00248 .

132. Couch V, Lindor NM, Kernes PS, Michels W. Von Hippel-Landau disease. Mayo Clin Proc. 2000;75:265-72.

133. Maynard MA, Ohh M. von Hippel-Lindau tumor suppressor protein and hypoxia-inducible factor in kidney cancer. Am J Nephrol. 2004;24:1-13. 
134. Stevens M, Oltean S. Modulation of receptor tyrosine kinase activity through alternative splicing of ligands and receptors in the VEGF-ANEGFR axis. Cells. 2019;8:E228. https://doi.org/10.3390/cells8040288.

135. Chang H-L, Lin J-C. SRSF1 and RBM4 differentially modulate the oncogenic effect of HIF1a in lung cancer cells through alternative splice mechanism. BBA Mol Cell Res. 2019;1866:118550.

136. Catena R, Lazarbal L, Larrayoz M, Molina E, Hermida J, Agorreta J, et al. VEGF121b and VEGF165b are weekly angiogenic isoforms of VEGF. Mol Cancer. 2010;9:320. https://doi.org/10.1186/1476-4598-9-320.

137. Wu X, Qiao B, Liu Q, Zghang W. Upregulation of extracellular matrix metalloproteinase inducer promotes hypoxia-induced epithelialmesenchymal transition in esophageal cancer. Mol Med Rep. 2015;12: 7419-24.

138. Bougatef F, Quemener C, Kellouche S, Naimi B, Podgorniak MP, Millot G, et al. EMMPRIN promotes angiogenesis through hypoxia-inducible factor2alpha-mediated regulation of soluble VEGF isoforms and their receptor VEGFR-2. Blood. 2009;114:5547-56.

139. Huang G, Zhou Z, Wang H, Kleinerman ES. CAPER-a alternative splicing regulates the expression of vascular endothelial growth factor165 in Ewing sarcoma cells. Cancer. 2012. https://doi.org/10.1002/cncr.26488.

140. Yao P, Wu J, Lindner D, Fox PL. Interplay between miR-574-3p and hnRNPL regulates VEGFA mRNA translation and tumorigenesis. Nucl Acids Res. 2017; 45:7950-64.

141. Zhou Q, Yu B, Anderson C, Huang ZP, Hanus J, et al. LncEGFL7OS regulates human angiogenesis by interacting with MAX at the EGFL7/miR-126 locus. Elife. 2019;8:e40470.

142. Thom RT, Rowe GC, Jang C, Safdar A, Arany Z. Hypoxic induction of vascular endothelial growth factor (VEGF) and angiogenesis in muscle by truncated peroxisome proliferator-activated receptor $y$ coactivator (PGC)-1a. J Biol Chem. 2014;289:8810-7.

143. Martinez-Redondo V, Pettersson AT, Ruas JL. The hitchhiker's guide to PGC1a isoform structure and biological functions. Diabetology. 2015:58:1969-77.

144. Stevens M, Oltean S. Modulation of receptor tyrosine kinase activity through alternative splicing of ligands and receptors in the VEGF-ANEGFR axis. Cells. 2019;288:10.3390/cells8040288.

145. Rossignol M, Gagnon ML, Klagsbrun M. Genomic organisation of human neuropilin-1 and neuropilin-2 genes: identification and distribution of splice variants and soluble isoforms. Genomics. 2000;70:211-22.

146. Aweimer A, Stachon T, Tannapfel A, Koller M, Truss MC, Stachon A. Regulation of VEGFR-2 sectreted by vascular endothelial cells derived from human BPH. Prost Cancer Prost Dis. 2012;15:157-64.

147. Gallo S, Arcidiacono MV, Tisato V, Piva R, Penolazzi L, Bosi C, et al. Upregulation of the alternative splicing factor NOVA2 in colorectal cancer vasculature. Onco Targets Ther. 2018;11:6049-56.

148. Angiolini F, Belloni E, Giordano M, Campioni M, Forneris F, Paronetto MP, et al. A novel L1CAM isoform with angiogenic activity generated by NOVA2-mediated alternative splicing. eLIFE. 2019;8:e44305. https://doi.org/ 10.7554/eLife.44305.

149. Lenglet M, Robriquet F, Schwarz K, Camps C, Couturier A, Hoogewijs D, et al. Identification of a new $\mathrm{VHL}$ exon and complex splicing alterations in familial erythrocytosis or von Hippel-Lindau disease. Blood. 2018;132: 469-83.

150. Chen X, Iliopoulos D, Zhang Q, Tang Q, Greeblatt MB, Hatziapostolou M, et al. XBP1 promotes triple-negative breast cancer by controlling HIF1a pathway. Nature. 2014;508:103-7.

151. Hirschfeld M, Zhang B, Jaeger M, Stamm S, Erbes T, Mayer S, et al. Hypoxiadependent mRNA expression pattern of splicing factor YT521 and its impact on oncological important target gene expression. Mol carcinogen. 2013;53: 883-92.

152. Weigand JE, Boeckel J-N, Gellert P, Dimmeler S. Hypoxia-induced alternative splicing in endothelial cells. PLOS ONE. 2012;7:e42697.

153. Xiang L, Xie G, Ou J, Wei X, Pan F, Liang H. The extra domain A of fibronectin increases VEGF-C expression in colorectal carcinoma involving the PI3KJAkt signaling pathway. PLOS ONE. 2012;7:e35378.

154. Losino N, Waisman A, Solari C, Luzzani C, Espinosa DF, Sassone A, et al. EDA-containing fibronectin increases proliferation of embryonic stem cells. PLOS ONE. 2013;8:e80681.

155. Dhuriya YK, Sharma D, Naik AA. Cellular demolition: proteins as molecular players of programmed cell death. Int J Biol Macromol. 2019;138:492-503.

156. Kanopka A. Cell survival: Interplay between hypoxia and pre-mRNA splicing. Exp Cell Res. 2017;356:187-91.
157. Ott M, Norberg E, Zhivotovsky B, Orrenius S. Mitochondrial targeting of tBID/BAX: a role for the TOM complex? Cell Death Differ. 2009:1075-82.

158. Lin JC, Tsao MF, Lin YJ. Differential impacts of alternative splicing networks on apoptosis. Int J Mol Sci. 2016;17:E20937.

159. Peciuliene I, Wilys L, Jakubauskiene E, Zaliauskiene L, Kanopka A. Hypoxia alters splicing of the cancer associated Fas gene. Exp Cell Res. 2019;380:29-35

160. Stevens M, Oltean S. Modulation of the apoptosis gene Blc-x function through alternative splicing. Front Genet. 2019;10:804. https://doi.org/10. 3389/fgene.2019.00804.

161. Dong Z, Wang J. Hypoxia selection of death-resistant cells, a role for BCl-xL. J Biol Chem. 2004;279:9215-21.

162. Xiao Q, Ford AL, Xu J, Yan P, Lee K-Y, Gonzales E, et al. Bcl-x pre-mRNA splicing regulates brain injury after neonatal hypoxia-ischemia. J Neurosci. 2012:32:13587-96.

163. Chen $\mathrm{N}$, Chen X, Huang $\mathrm{R}$, Zeng $\mathrm{H}$, Gong J, Meng W, et al. BCL-XL is a target gene regulated by hypoxia-inducible factor-1a. J Biol Chem. 2009;284: 10004-12.

164. Gang H, Dhingra R, Lin J, Hai Y, Aviv Y, Margulets V, et al. PDK2-mediated alternative splicing switches Bnip3 from cell death to cell survival. J Cell Biol. 2015;210:1101-15.

165. Gang H, Hai Y, Dhingra R, Gordon JW, Yurkova N. A novel hypoxia-inducible spliced variant of mitochondrial death gene Bnip3 promotes survival of ventricular myocytes. Circ Res. 2011;108:1084-92.

166. Field JT, Martens MD, Mughal W, Hai Y, Chapman D, Hatch GM, et al. Misoprostol regulates Bnip3 repression and alternative splicing to control cellular calcium homeostasis during hypoxic stress. Cell Death Discov. 2018; 4:98. https://doi.org/10.1038/s41420-018-0104-z.

167. Gneo L, Ruggeri P, Cappabianca L, Farina AR, Di lanni N, Mackay AR. TRAIL induces pro-apoptotic crosstalk between the TRAlL-receptor signaling pathway and TrkAIII in SH-SY5Y cells, unveiling a potential therapeutic "Achilles heel" for the TrkAlll oncoprotein in neuroblastoma. Oncotarget. 2016;7:80820-41.

168. Ruggeri P, Farina AR, Di lanni N, Cappabianca L, Ragone M, lanni G, et al. The TrkAlll oncoprotein inhibits mitochondrial free-radical ROS-induced death of SH-SY5Y neuroblastoma cells by augmenting SOD-2 expression and activity at the mitochondria, within the context of a tumor stem celllike phenotype. PLOS ONE. 2014;15:e94568.

169. Farina AR, Cappabianca L, Ruggeri P, Gneo L, Maccarone R, Mackay AR, et al. Retrograde TrkAlll transport from ERGIC to ER: a relocalization mechanism for oncogenic activity. Oncotarget. 2015;6:35636-51.

170. Tyson-Capper A, Gautrey H. Regulation of Mcl-1 alternative splicing nu hnRNP F, H1 and K in breast cancer cells. RNA Biol. 2018;15:1448-57.

171. Saint-Martin A, Castaneda CM, Robles-Flores M. The role of hypoxiainducible factors in cancer resistance. J Cell Signal. 2017;2:1. https://doi.org/ 10.4172/2161-0495.1000154.

172. Koumenis C, Naczki C, Koritzinsky M, Rastani S, Diehl A, Sonenberg N, et al. Regulation of protein synthesis by hypoxia via activation of the endoplasmic reticulum kinase PERK and phosphorylation of the translation initiation factor e1F2alpha. Mol Cell Biol. 2002;22:7405-16.

173. Ma L, Shan Y, Ma H, ElShoura H, Nafees M, Yang K, et al. Identification of a novel splice variant of the human mushashi-1 gene. Onocol Letters. 2018; 16:5441-8.

174. Zhou X, Wu W, Li H, Cheng Y, Wei N, Zong J, Feng X, et al. Transcriptome analysis of alternative splicing events regulated by SRSF10 reveals positiondependent splicing modulation. Nucl Acids Res. 2014;42:4019-30.

175. Yan X, Zhou R, Ma Z. Autophagy-cell survival and death. Adv Exp Med Biol. 2019;1206:667-96

176. Liu H, Zhang Z, Xiong W, Zhang L, Du Y, Liu Y, et al. Long non-coding RNA MALAT1 mediates hypoxia-induced pro-survival autophagy of endometrial stromal cells in endometriosis. J Cell Mol Med. 2019;23:439-52.

177. Zhou L, Guo J, Jia R. Oncogene SRSF3 suppresses autophagy via inhibiting BECN1 expression. Biochem Biophys Res Commun. 2019;509:966-72.

178. Noman MZ, Hasmim M, Messai Y, Terry S, Kieda C, Janji B, et al. Hypoxia: a key player in antitumor immune response. A review in the theme: Cellular responses to hypoxia. Am J Phisiol Cell Physiol. 2015;309:C569-79.

179. Labiano S, Palazon A, Bolanos E, Azpilikueta A, Sanchez-Paulete AR, MoralesKastresana A, et al. Hypoxia-induced soluble CD137 in malignant cells blocks CD137L-costimulation as an immune escape mechanism. Oncoimmunol. 2016:5:1-10. 
180. Garziera M, Scarabel L, Toffoli G. Hypoxic modulation of HLA-G expression through the metabolic sensor HIF-1 in human cancer cells. J Immunol Res. 2017;2017. https://doi.org/10.1155/2017/4587520.

181. Cubillos-Ruiz SPC, Rutkowski MR, Chopra S, Perales-Puchalt A, Song M, et al. ER stress sensor XPB1 controls anti-tumor immunity by disrupting dendritic cell homeostasis. Cell. 2015;161:1527-38.

182. Shen $X$, Zhang L, Li J, Li Y, Wang Y, Xu ZX. Recent findings in the regulation of programmed death ligand 1 expression. Front Immunol. 2019;10:1337. https://doi.org/10.3389/fimmu.2019.01337.

183. Gong B, Kiyotani K, Sakata S, Nagano S, Kumehara S, Babe S, et al. Secreted PD-L1 variants mediate resistance to PD-L1 blockade therapy in non-small cell lung cancer. J Exp Med. 2019;216:982-1000.

184. Al Tameemi W, Dale TP, Al-Jumaily RMK, Forsyth NR. Hypoxia-modified cancer cell metabolism. Front Cell Dev Biol. 2019;7:4. https://doi.org/10. 3389/fcell.2019.00004.

185. Williams AL, Khadka V, Shohet RV. HIF1 mediates a switch in pyruvate kinase isoforms after myocardial infarction. Physiol Genomics. 2018;50:479-94.

186. Luo W, Semenza GL. Pyruvate kinase M2 regulates glucose metabolism by functioning as a coactivator for hypoxia-inducible factor 1 in cancer cells. Oncotarget. 2011;5:551-6.

187. Palazzo AF, Mahadevan K. Alternative splicing rewires cellular metabolism to turn on the Warburg effect. Biomed Res. 2012;23:25-30.

188. Su C-H, Hung K-Y, Hung S-C, Tarn W-Y. RBM4 regulates neuronal differentiation of mesenchymal stem cells by modulating alternative splicing of pyruvate kinase M. Mol Cell Biol. 2017;37:e00466-16. https://doi. org/10.1128/MCB.00466-16.

189. Olson KA, Schell JC, Rutter J. Pyruvate and metabolic flexibility: Illuminating a path toward selective cancer therapies. Trends Biochem Sci. 2016:41:219-30.

190. Gray LR, Tompkins SC, Taylor EB. Regulation of pyruvate metabolism and human disease. Cell Mol Life Sci. 2014;71:2577-604.

191. McCommis KS, Finck BN. Mitochondrial pyruvate transport: a historical perspective and future research directions. Biochem J. 2015;466:443-54.

192. Eyassu F, Angione C. Modelling pyruvate dehydrogenase under hypoxia and its role in cancer metabolism. R Soc open Sci. 2017;4:170360. https:// doi.org/10.1098/rsos.170360.

193. Farina AR, Cappabianca L, Gneo L, Ruggeri P, Mackay AR. TrkAlll signals endoplasmic stress to the mitochondria in neuroblastoma cells, resulting in glycolytic metabolic adaptation. Oncotarget. 2017;9:8368-90.

194. Biamonti G, Maita L, Montecucco A. The KREBS cycle connection: Reciprocal influence between alternative splicing programs and cell metabolism. Front Oncol. 2018:8:408 https://doi.org/10.3389/fonc.2018.00408.

195. Gabut M, Mine M, Marsac C, Brivet M, Tazi J, et al. The SR protein SC35 is responsible for aberrant splicing of the E1a pyruvate dehydrogenase mRNA in a case of mental retardation with lactic acidosis. Mol Cell Biol. 2005;25: 3286-94.

196. Pearson GW. Control of invasion by epithelila-to-mesenchymal transition programs during metastasis. J Clin Med. 2019;8:646. https://doi.org/10.3390/ cjm8050646.

197. Chen X, Zhang S, Wang Z, Wang F, Cao X, Wu Q, et al. Supervillin promotes epithelial-mesenchymal transition and metastasis of hepatocellular carcinoma in hypoxia via activation of the RhoA/ROCKERK/p38 pathways. J Exp Clin Cancer Res. 2018;37:128. https://doi.org/ 10.1186/s13046-018-0787-2.

198. Shih J-W, Kung H-J. Long non-coding RNA and tumor hypoxia: new players ushered toward an old arena. J Biomed Sci. 2017;24:53. https://doi.org/10. 1186/s12929-017-0358-4.

199. Romero-Barrios N, Legascue MF, Benhamed M, Ariel F, Crespi M. Survey and summary splicing regulation by long coding RNAs. Nucl Acids Res. 2018;46: 2169-84.

200. Beltran M, Puig I, Pena C, Garcia JM, Alvarez AB, Pena R, et al. A natural antisense transcript regulates Zeb2/Sip1 gene expression during Snail-1-induced epithelial to mesenchymal transition. Genes Dev. 2008; 22:756-69.

201. Stone JK, Kin JH, Vudakin L, Richard A, Giannini HK, Lim SS, et al. Hypoxia induces cancer cell-specific chromatin interactions and increases MALAT1 expression in breast cancer cells. J Biol Chem. 2019;294:11213-24.

202. Heery R, Finn SP, Cuffe S, Gray SG. Long non-coding RNAs: Key regulators of epithelial-mesenchymal transition, tumour drug resistance and cancer stem cells. Cancers. 2017:9:38. https://doi.org/10.3390/cancers9040038.
203. Wu F, Gao H, Liu K, Gao B, Ren H, Li Z, et al. The IncRNA ZEB2-AS1 is upregulated in gastric cancer and effects cell proliferation and invasion via miR-143/HIF1a axis. Onco Targets Ther. 2019;12:657-67.

204. Hu ZY, Wang XY, Guo WB, Xie LY, Huang YQ, Liu YP, et al. Long coding RNA MALAT1 increases AKAP-9 expression by promoting SRPK1-catalyzed SRSF1 phosphorylation in colorectal cancer cells. Oncotarget. 2016;7:11733-43.

205. Schor IE, Lières D, Risso GJ, Pawellek A, Ule J, Lamond Al, et al. Perturbation of chromatin structure globally affects localization and recruitment of splicing factors. PLOS ONE. 2012;7:e48084.

206. Xiping Z, Bo C, Shifeng Y, Feijiang Y, Hongjian Y, Qihui C, et al. Roles of MALAT-1 in development and migration of triple negative and Her-2 positive breast cancer. Oncotarget. 2018;9:2255-67.

207. Meredith EK, Balas MM, Sindy K, Haislop K, Johnson AM. An RNA matchmaker protein regulates the activity of the long noncoding RNA HOTAIR. RNA. 2016;22:995-1010.

208. Xu X, Tan X, Tampe B, Sanchez B, Zeisberg M, Zeisberg EM. Snail is a direct target of hypoxia-inducible factor 1a (HIF1a) in hypoxia-induced endothelial to mesenchymal transition of human coronary endothelial cells. J Biol Chem. 2015:290:16653-64.

209. Lundgren K, Nordenskjold B, Landberg G. Hypoxia, snail and incomplete epithelial-mesenchymal transition in breast cancer. Br J Cancer. 2009;101:1769-81.

210. Guo Y, Hu Y, Hu M, He M, Li B. Long non-coding RNA ZEB2-AS1 promotes proliferation and inhibits apoptosis in human lung cancer cells. Onc Letters. 2018;15:5220-6.

211. Warzecha CC, Jiang P, Amirikian K, Dittmar KA, Lu H, Shen S, et al. An ESRPregulated splicing programme is abrogated during the epithelialmesenchymal transition. EMBO J. 2010;29:3286-300.

212. Goel HL, Gritsko T, Pursell B, Chang C, Shultz LD, Greiner DL, et al. Regulated splicing of the a6 integrin cytoplasmic domain determines the fate of breast cancer stem cells. Cell Reports. 2014;7:747-61.

213. Matos ML, Lapyckyj L, Rosso M, Besso MJ, Mencucci MV, Briggiler Cl, et al. Identification of a novel human E-cadherin splice variant and assessment of its effects upon EMT-related events. J Cell Physiol. 2017;232:1368-86.

214. Pradella D, Naro C, Sette C, Ghigna C. EMT and stemness: flexible processes tuned by alternative splicing in development and cancer progression. Mol Cancer. 2017;16:8. https://doi.org/10.1186/s12943-016-0579-2.

215. Mimeault M, Batra SK. Hypoxia-inducing factors as master regulators of stemness properties and altered metabolism of cancer- and metastasisinitiating cells. J Cell Mol Med. 2013;17:30-54.

216. Macharia LW, Wanjiru CM, Mureithi MW, Pereira CM, Ferrer VP, Moura-Neto $V$, et al. MicroRNAs, hypoxia and the stem-like state as contributors to cancer aggressiveness. Front Genet. 2019;10. https://doi.org/10.3389/fgene. 2019.00125

217. Yoshimoto S, Tanaka F, Morita H, Hiraki A, Hashimoto S. Hypoxiainduced HF-1a and ZEB1 are critical for the malignant transformation of ameloblastoma via TGF- $\beta$-dependent EMT. Cancer Med. 2019;8: $7822-32$.

218. Preca B-T, Bajdak K, Mock K, Sundararajan V, Pfannstiel J, Maurer J, et al. A self-enforcing CD44s/ZEB1 feedback loop maintains EMT and stemness properties in cancer cells. Int J Cancer. 2015;137:2566-77.

219. Hu X, Wu R, Shehadeh LA, Zhou Q, Jiang C, Huang X et al. Severe hypoxia exerts parallel and cell-specific regulation of gene expression and alternative splicing in human mesenchymal stem cells. BMC Genomics 2014; 15:303 10-1186/1471-2164-15-303.

220. Ge Y, Weygant N, Qu D, May R, Berry WL, Yao J, et al. Alternative splice variants of DCLK1 mark cancer stem cells, promote self-renewal and drugresistance, and can be targeted to inhibit tumorigenesis in kidney cancer. Int J Cancer. 2018;143:1162-75.

221. Farina AR, Di lanni N, Cappabianca L, Ruggeri P, Ragone M, lanni G, et al. TrkAlll promotes microtubule nucleation and assembly at the centrosome in SH-SY5Y neuroblastoma cells, contributing to an undifferentiated anaplastic phenotype. Biomed Res Int. 2013;2013:740187. https://doi.org/10.1155/2013/ 740187.

222. Moller-Levet CS, Betts GNJ, Harris AL, Homer JJ, West CM, Miller CJ. Exon array analysis of head and neck cancers identifies a hypoxia regulated splice variant of LAMA3 associated with poor prognosis. PLOS Comput Biol. 2009; 11:e1000571. https://doi.org/10.1371/journal.pcbi.1000571.

223. Wang ZN, Liu D, Yin B, Ju W-Y, Qui H-Z, Xiao Y, et al. High expression of PTBP1 promote invasion of colorectal cancer by alternative splicing of cortactin. Oncotarget. 2017;3:36185-202. 
224. Van Rossum AGSH, de Graaf JH, Schuuring-Scholtes E, Kluin PM, Fan Y-X, Zhan $\mathrm{X}$, et al. Alternative splicing of the actin binding domain of human cortactin affects cell migration. J Biol Chem. 2003;278:45627-79.

225. Hoesel B, Schmidt JA. The complexity of NF-kB signaling in inflammation and cancer. Mol Cancer. 2013;12:86.

226. Mamlouk S, Wielockx B. Hypoxia-inducible factors as key regulators of tumor inflammation. Int J Cancer. 2013;132:2721-9.

227. Mahiddine K, Blaisdell A, Ma S, Créquer-Grandhomme A, Lowell CA Erlebacher A. Relief of tumor hypoxia unleashes the tumoricidal potential of neutrophils. J Clin Invest. 2020;130:389-403.

228. Lewis C, Murdoch C. Macrophage responses to hypoxia. Am J Pathol. 2005; 167:627-35.

229. Raggi F, Pelassa S, Pierobon D, Penco F, Gattorno N, Novelli F, et al. Regulation of human macrophage M1-M2 polarization balance by hypoxia and the triggering receptor expressed on myeloid cells-1. Front Immunol. 2017:8:1097. https://doi.org/10.3389/fimmu.2017.01097.

230. Rahat MA, Bitterman $H$, Lahat N. Molecular mechanisms regulating macrophage response to hypoxia. Front Immunol. 2011;2:45. https://doi.org/ 10.3389/fimmu.2011.00045

231. Ke $X$, Chen C, Song Y, Cai Q, Li J, Tang Y, et al. Hypoxia modifies the polarization of macrophages and their inflammatory microenvironment, and inhibits malignant behavior in cancer cells. Oncol Lett. 2019;18: $5871-8$.

232. Zhang J, Cao J, Ma S, Dong R, Meng W, Ying M, et al. Tumor hypoxia enhances non-small cell lung cancer metastasis by selectively promoting macrophage M2 polarization through the activation of ERK signaling. Oncotarget. 2014:5:9664-77.

233. Louis S IV, Dickson AM. Bohjanen PR and Wilusz. CELFish ways to modulate mRNA decay. Biochim Biophys Acta. 1829;2013:695-707.

234. Lin J, Hu Y, Nunez S, Foulkes AS, Cieply B, Xue C, et al. Transcriptome-wide analysis reveals modulation of human macrophage inflammatory phenotype through alternative splicing. Arterioscler Thromb Vasc Biol. 2016. 36:1434-47.

235. Lahat N, Rahat MA, Ballan M, Weiss-Cerem L, Engelmayer M, et al. Hypoxia reduces CD80 expression on monocytes but enhances their LPS-stimulated TNF-alpha secretion. J Leuk Biol. 2003;74:197-205.

236. Tang AC, Saferali A, He G, Sandford AJ, Strug JL, Turvey SE. Endoplasmic reticulum stress and chemokine production in cystic fibrosis airways cells: Regulation by STAT3 modulation. J Infect Dis. 2017;215:293-302.

237. Liu F, Dai M, Xu Q, Zhu X, Zhou Y, Jiang S, et al. SRSF10-mediated IL1RAP alternative splicing regulates cervical cancer oncogenesis via mIL1RAP-NFKB-CD47 axis. Oncogene. 2018;37:2394-409.

238. Shomron N, Alberstein M, Reznik M, Ast G. Stress alters the subcellular distribution of hSlu7 and thus modulates alternative splicing. J Cell Sci. 2005:118:1151-9.

239. Dutertre M, Sanchez G, Barbier J, Corcos L, Auboeuf D. The emerging role of pre-messenger RNA splicing in stress responses: sending alternative messages and silent messengers. RNA Biol. 2011:8:740-7.

240. Jimenez M, Urtasun R, Elizalde M, Azkona M, Latasa MU, Uriate I, et al. Splicing events in the control of genome integrity: role of SLU7 truncated SRSF3 proteins. Nucl Acids Res. 2019;47:3450-66.

241. Jain S, Wheeler JR, Walters RW, Agawaral A, Barsic A, Parker R. ATPasemodulated stress granules contain a diverse proteome and substructure. Cell. 2016;164:487-98.

242. Salas-Armentteros I, Barroso SI, Rondon AG, Pérez M, Andùjar E, Luna R, et al. Depletion of the MFAP1/SPP381 splicing factor causes R-loopindependent genome instability. Cell Rep. 2019;28:1551-63.

243. Lu Y, Chu A, Turker MS, Glazer PM. Hypoxia-induced epigenetic regulation and silencing of the BRCA1 promoter. Mol Cell Biol. 2011;31:3339-50.

244. Sami E, Paul BT, Koziol JA, ElShamy WM. The immunosuppressive microenvironment in BRCA1-IRIS-overexpressing TNBC tumors is induced by bidirectional interaction with tumor-associated macrophages. Cancer Res. 2020. https://doi.org/10.1158/0008-5472.CAN-19-2374.

245. Brinda RS, Gibson SL, Meng A, Westermark U, Jasin M, Pierce AJ, et al. Hypoxia-induced down-regulation of BRCA1 expression by E2Fs. Cancer Res. 2005:65:11597-604.

246. Shimizu Y, Mullins N, Blanchard Z, ElShamy WM. BRCA1/p220 loss triggers BRCA1-IRIS overexpression via mRNA stabilization in breast cancer cells. Oncotarget. 2012;3:299-313.

247. Li AG, Murphy EC, Culhane AC, Powell E, Wang H, Bronson RT, et al. BRCA1IRIS promotes human tumor progression through PTEN blockade and HIF- 1a activation. Proc Natl Acad Sci USA. 2018;115:41. https://doi.org/10.1073/ pnas. 1807112115

248. Farina AR, Tacconelli A, Cappabianca L, Cea G, Panella S, Chioda A, et al. The alternative TrkAlll splice variant targets the centrosome and promotes genetic instability. Mol Cell Biol. 2009;29:4812-30.

249. Fukumura D, Jain RK. Tumor microvasculature and microenvironment: targets for anti-angiogenesis and normalization. Microvasc Res. 2007;74: $72-84$.

250. Jing $X$, Yang F, Shao C, Wei $K$, Xie M, Shen $H$, et al. Role of hypoxia in cancer therapy by regulating the tumor microenvironment. Mol Cancer. 2019;18:157. https://doi.org/10.1186/s12943-019-1089-9.

251. Vordermark D. Hypoxia-specific targets in cancer therapy: role of splice variants. BMC Med. 2010;8:45

252. Anufrieva KS, Shender VO, Arapidi GP, Pavlyukov MS, Shakhparonov MI, Schnaider PV, et al. Therapy-induced stress response is associated with downregulation of pre-mRNA splicing in cancer cells. Genome Med. 2018; 10:49. https://doi.org/10.1186/s13073-018-0557-y.

253. Park J, Chung Y-J. Identification of neoantigens derived from alternative splicing and RNA modification. Genom Inform. 2019;17:e23. https://doi.org/ 10.5808/Gl.2019.17.3.e23

254. Robinson TJ, Freedman JA, Al Abo M, Deveaux AE, LaCroix B, Patierno BM, et al. Alternative RNA splicing as a potential major source of untapped molecular targets in precision oncology and cancer disparities. Clin Cancer Res. 2019;25. https://doi.org/10.1158/1078-0432.CCR-18-2445.

255. Villegas-Ruiz V, Juarez-Mendez S. Alternative RNA splicing: New approaches for molecular marker discovery in cancer. Intech Open. 2018. https://doi. org/10.5772/intechopen.74415.

256. Black AJ, Gamarra JR, Giudice J. More than a messenger: Alternative splicing as a therapeutic target. BBA Gene Reg Mechan. 2019:1862:184395. https:// doi.org/10.1016/j.bbagrm.2019.06.006

257. Dales J-P, Beaufils N, Silvy M, Picard C, Pauly V, Pradel V, et al. Hypoxia inducible factor 1a gene (HIF1a) splice variants: potential prognostic biomarkers in breast cancer. BMC Med. 2010;8:44. https://doi.org/10.1186/ 1741-7015-8-44.

258. Qui G-Z, Jin M-Z, Dai J-X, Sun W, Feng J-H, Jin W-L. Reprogramming of the tumor in the hypoxic niche: The emerging concept and associated therapeutic strategies. Trends Pharmacol Sci. 2017;38:669-86.

259. Fix SM, Papadopoulou V, Velds H, Kasoji SK, Rivera JN, Borden MA, et al. Oxygen microbubbles improve radiotherapy tumor control in a rat fibrosarcoma model-a preliminary study. PLOS ONE. 2018;13:e0195667.

260. Ho X-J, Chu S-W, Liao E-C, Fan C-H, Chan H-L, Wei KC, et al. Normalization of tumor vasculature by oxygen microbubbles with ultrasound. Theranostics. 2019;9:7370-83.

261. Wang H, Li J, Wang Y, Gong X, Xu X, Wang J, et al. Nanoparticles-mediated reoxygenation strategy relieves tumor hypoxia for enhanced cancer therapy. J Control Release. 2020;319:25-45.

262. Mazzone M, Dettori D, De Oliviera RL, Loges S, Schmidt T, Jonckx B, et al. Heterozygous deficiency of PHD2 restores tumor oxygenation and inhibits metastasis via endothelial normalization. Cell. 2009;136:839-51.

263. Chen S-J, Hoffman NE, Shanmughapriya S, Bao L, Keefer K, Conrad K, et al. A splice variant of the human ion channel TRPM2 modulates neuroblastoma tumor growth through hypoxia-inducible factor (HIF)-1/2a. J Biol Chem. 2014:289:36284-302

264. Jeong W, Rapisarda A, Park SR, Kinders RJ, Chen A, Melillo G, et al. Pilot trial of EZN-2968, an antisense oligonucleotide inhibitor of hypoxia-inducible factor-1 alpha (HIF-1a), in patients with refractory solid tumors. Cancer Chemother Pharmacol. 2014;73:343-8.

265. Coltella N, Valsecchi R, Ponente M, Ponzoni M, Bernardi R. Synergistic leukemia eradication by combined treatment with retinoic acid and HIF inhibition by EZN-2208 (PEG-SN38) in preclinical models of PML-RARa and PLZF-RARa-driven leukemia. Clin Cancer Res. 2015;21:3685-94.

266. Rapisarda A, Uranchimeg B, Sordet O, Pommier Y, Shoemaker RH, Melillo G. Topoisomerase I-mediated inhibition of hypoxia-inducible factor 1: mechanism and therapeutic implications. Cancer Res. 2004;64:1475-82.

267. Fu B, Xue J, Li Z, Shi X, Jiang B-H, Fang J. Chrysin inhibits expression of hypoxia-inducible factor-1alpha through reducing hypoxia-inducible factorlalpha stability and inhibiting its protein synthesis. Mol Cancer Ther. 2007;6: 220-6.

268. Lee S-H, Jee J-G, Bae J-S, Liu K-H, Lee YM. A group of novel HIF-1a inhibitors, glyceollins, blocks HIF-1a synthesis and decreases its stability via 
inhibition of the PI3K/AKT/mTOR pathway and Hsp90 binding. J Cell Physiol. 2015;230:853-62

269. Poch A, Villanelo F, Henriquez S, Kohen P, Munoz A, Strauss JF 3rd, et al. Molecular modelling predicts that 2-methoxyestradiol disrupts HIF function by binding to the PAS-B domain. Steroids. 2019;144:21-9.

270. Narita T, Yin S, Gelin CF, Moreno CS, Yepes M, Nicolaou KC, et al. Identification of a novel small molecule HIF-1alpha translation inhibitor. Clin Cancer Res. 2009;15:6128-36.

271. Lang S, Moser C, Gaumann A, Klein D, Glockzin G, Popp FC, et al. Targeting heat shock protein 90 in pancreatic cancer impairs insulin-like growth factor-1 receptor signaling, disrupts and interleukin-6/signal-transducer and activator of transcription 3/hypoxia-inducible factor-1alpha autocrine loop, and reduces orthotopic tumor growth. Clin Cancer Res. 2007;13:6459-68.

272. Bohonowych JES, Peng S, Gopal U, Hance MW, Wing SB, Argraves KM, et al. Comparative analysis of novel and conventional Hsp90 inhibitors on HIF activity and angiogenic potential in clear cell renal cell carcinoma: Implications for clinical evaluation. BMC Cancer. 2011;11:520. https://doi.org/ 10.1186/1471-2407-11-520.

273. Hutt DM, Roth DM, Vignaud H, Cullin C. Bouchecareilh. The histone deacetylase inhibitor, Vorinostat represses hypoxia inducible factor 1 alpha expression through translational inhibition. PLOS ONE. 2014;9:e106224.

274. Mukherjee A, Martin SG. The thioredoxin system: a ky target in tumor endothelila cells. Br J Radiol. 2008:81:S57-68.

275. Yu X, Zhao R, Lin S, Bai X, Zhang L, Yuan S, et al. CXCL16 induces angiogenesis in autocrine signaling pathway involving hypoxia-inducible factor 1a in human umbilical vein endothelial cells. Oncol Rep. 2016;35:1557-65.

276. Lee K, Kang JE, Park S-K, Jin Y, Chung K-S, Kim HM, et al. LW6, a novel HIF-1 inhibitor, promotes proteosomal degradation of HIF-1alpha via ubiquitination of VHL in a colon cancer cell line. Biochem Pharmacol. 2010; 80:982-9.

277. Sica V, Bravo San-Pedro JM, Izzo V, Pol J, Pierredon S, Enot D, et al. Lethal poisoning of cancer cells by respiratory chain inhibition plus dimethyl aketogluterate. Cell Rep. 2019;27:820-34.

278. Griggio V, Vitale C, Todaro M, Riganti C, Kopecka J, Salvetti C, et al. HIF-1a is over-expressed in leukemic cells from TP53-disrupted patients and is a promising therapeutic target in chronic lymphocytic leukemia. Haematologica. 2020;105:1042-54.

279. Miranda E, Nordgren IK, Male AL, Lawrence CE, Hoakwie F, Cuda F, et al. A cyclic peptide inhibitor of HIF-1 heterodimerization that inhibits hypoxia signaling in cancer cells. J Am Chem Soc. 2013;135:10418-25.

280. Scheuermann TH, Li Q, Ma H-W, Key J, Zhang L, Chen R, et al. Allosteric inhibition of hypoxia inducible factor-2 with small molecules. Nat Chem Biol. 2013;9:271-6.

281. Lee K, Zhang H, Qian DZ, Rey S, Liu JO, Semenza GL. Acriflavine inhibits HIF1 dimerization, tumor growth, and vascularization. Proc Natl Acad Sci USA. 2009;106:17910-5.

282. Pang Y, Yang C, Schovanek J, Wang H, Bullova P, Caisova V, et al. Anthracyclins suppress pheochromocytoma cell characteristics, including metastasis, through inhibition of the hypoxia signaling pathway. Oncotarget. 2017;8:22313-24.

283. Kong D, Park EJ, Stephen AG, Calvani M, Cardellina JH, Monks A, et al. Echinomycin, a small-molecule inhibitor of hypoxia-inducible factor-1 DNAbinding activity. Cancer Res. 2005;65:9047-55.

284. Staab A, Loeffler J, Said HM, Diehlmann D, Katzer A, Beyer M, et al. Effects of HIF-1 inhibition by chetomin on hypoxia-related transcription and radiosensitivity in HT1080 human fibrosarcoma cells. BMC Cancer. 2007;7: 213. https://doi.org/10.1186/1471-2407-7-213.

285. Minegishi H, Fukashiro S, Ban HS, Nakamura H. Discovery of Indenopyrazoles as a new class of hypoxia inducible factor (HIF)-1 inhibitors. ACS Med Chem Lett. 2013;4:297-301.

286. Li SH, Shin DH, Chun Y-S, Lee MK, Kim M-S, Park JW, et al. A novel mode of action of YC-1 in HIF inhibition: stimulation of FlH-dependent p300 dissociation from HIF-1(alpha). Mol Cancer Ther. 2008;7:3729-38.

287. Moreno-Manzano V, Rodriguez-Jiminez FJ, Acena-Bonilla JL, Fustero-Lardies S, Erceg S, Dopazo J, et al. FM19G11, a new hypoxia-inducible factor (HIF) modulator, affects stem cell differentiation status. J Biol Chem. 2010;285: $1333-42$.

288. Chau N-M, Rogers P, Aherne W, Carroll V, Collins I, McDonald E, et al. Identification of novel small molecule inhibitors of hypoxia-inducible factor1 that differentially block hypoxia-inducible factor-1 activity and hypoxia- inducible factor-1alpha induction in response to hypoxic stress and growth factors. Cancer Res. 2005;65:4918-28.

289. Ban HS, Lim B-K, Lee H, Kim HM, Harmalkar D, Nam M, et al. The novel hypoxia-inducible factor-1a inhibitor IDF-1174 regulates cancer metabolism, thereby suppressing tumor growth. Cell Death Dis. 2017;8:e2843.

290. Lim LY-M, J-H YY-S, Park J-W. Antihepatoma activity of Chaetocin due to deregulated splicing of hypoxia-inducible factor 1a pre-mRNA in mice and in vitro. Hepatol. 2011;53:171-80.

291. Isham CR, Tibodeau JD, Bossou AR, Merchan JR, Bible KC. The anticancer effects of chaetocin are independent of programmed cell death and hypoxia, and are associated with inhibition of endothelial cell proliferation. Br J Cancer. 2012;106:314-23.

292. Zhao H, Zhang B, Ma L-F, Shi L-M, Zhan Z-J. Cytotoxic spliceostatin analogs from pseudomonas Sp. Chem Niodivers. 2019;16:e1900266.

293. Lagisetti C, Yermolina MV, Sharma LK, Palacios G, Prigaro BJ, Webb TR, et al. Pre-mRNA splicing-modulatory pharmacophores: the total synthesis of herboxidiene, a pladienolide-herboxidiene hybrid analogue and related derivatives. ACS Chem Biol. 2014;9:643-8.

294. Effenberger KA, Andreson DD, Bray WM, Prichard BE, Ma N, Adams MS, et al. Coherence between cellular responses and in vitro splicing inhibition for the anti-tumor drug pladienolide B and its analogs. J Biol Chem. 2014;289:1938-47.

295. Thurman M, van Doorn J, Danzer B, Webb TR, Stamm S. Changes in alternative splicing as pharmacodynamic markers for sudemycin D6. Biomark Insights. 2017;12:117271917730557. https://doi.org/10.1177/1177271917730557.

296. O'Brien K, Matlin AJ, Lowell AM, Moore MJ. The biflavonoid Isoginkgetin is a general inhibitor of pre-mRNA splicing. J Biol Chem. 2008;283:33147-5.

297. Absmeier E, Santos KF, Wahl MC. Functions and regulation of the Brr2 RNA helicase during splicing. Cell Cycle. 2016;15:3362-77.

298. Ito M, Iwatani M, Yamamoto T, Tanaka T, Kawamoto Y, Morishita D, et al. Discovery of spiro [indole-3,2'-pyrrolidin]-2(1H)-one based inhibitors targeting Brr2, a core component of the U5 snRNP. Bioorg Med Chem. 2017;25:4753-67.

299. Iwatani-Yoshihara M, Ito M, Klein MG, Yamamoto T, Yonemori K, Tanaka T, et al. Discovery of allosteric inhibitors targeting the spliceosomal RNA helicase Brr2. J Med Chem. 2017;60:5759-71.

300. Bebee TW, Dominguez CE, Samadzadeh-Tarighat S, Akehurst KL, Chandler DS. Hypoxia is a modifier of SMN2 splicing and disease severity in a sever SMA mouse model. Hum Mol Genet. 2012;21:4301-13.

301. Ludoph AC, Wurster CD. Therapeutic advances in SMA. Curr Opin Neurol. 2019:32:777-81.

302. Takakura K, Kawamura A, Torisu Y, Koido S, Yahagi N, Saruta M. The clinical potential of oligonucleotide therapeutics against pancreatic cancer. Int J Mol Sci. 2019;20:3331. https://doi.org/10.3390/ijms20133331.

303. Farina AR, Tacconelli A, Cappabianca L, Cea G, Chioda A, Romanelli A, et al. The neuroblastoma tumor-suppressor TrkAl and its oncogenic alternative TrkAlll splice variant exhibit geldanamycin-sensitive interactions with Hsp90 in human neuroblastoma cells. Oncogene. 2009;28:4075-94.

304. Dewaele M, Tabaglio T, Willekens K, Bezzi M, Teo SX, Low DH, et al. Antisense oligonucleotide-mediated MDM4 exon 6 skipping impairs tumor growth. J Clin Invest. 2016;126:68-84.

305. Diouf B, Lin W, Goktug A, Grace CRR, Waddell MB, Bao J, et al. Alteration of RNA splicing by small-molecule inhibitors of the interaction between NHP2L1 and U4. SLAS Discov. 2018:23:164-73.

306. Shkreta L, Chabot B. The RNA splicing response to DNA damage. Biomolecules. 2015;5:2935-77.

307. Zhao R, Follows GA, Beer PA, Scott LM, Huntly BJ, Green AR, et al. Inhibition of the BCl-XL deamidation pathway in myeloproliferative disorders. N Engl J Med. 2008:359:2778-89.

308. Chang WH, Liu T-C, Yang W-K, Lee C-C, Lin Y-H, Chen TY, et al. Amiloride modulates alternative splicing in leukemic cells and resensitizes BcrAblT351I mutant cells to imatib. Cancer Res. 2011;71:383-92.

309. Xargay-Torrent S, Lopèz-Guerra M, Rosich L, Montraveta A, Roldàn J, Rodriguez J, et al. The splicing modulator sudemycin induces a specific antitumor response and cooperates with ibrutinib in chronic lymphocytic leukemia. Oncotarget. 2015;6:22734-49.

310. Giulietti M, Piva F, D'Antonio M, D'Onorio De Meo P, Paoletti D, Castrignano T, et al. SpliceAid-F: a database of human splicing factors and their RNA binding sites. Nucleic Acids Res. 2013;41:D125-31.

311. Dreyfuss G, Matunis MJ, Pinol-Roma S, Burd CG. hnRNP proteins and biogenesis of mRNA. Annu Rev Biochem. 1993;62:289-321.

312. Gorlich D, Mattaj IW. Nucelocytoplasmic transport. Science. 1996;271:1513-8. 
313. Azmi AS, Aboukameel A, Bao B, Sarkar FH, Philip PA, Kauffman M, et al. Selective inhibitors of nuclear export block pancreatic cancer cell proliferation and reduce tumor growth in mice. Gastroenterology. 2013;144: 447-56.

314. Cloe A, Chen L, Li Y, Liu H, Cheng JX. Identification of specific Hnrnps as novel therapeutic targets and responsive indicators of KPT330 (Selinexor) in leukemia. Blood. 2016;128:1657.

315. Shu B, Zeng P, Kang S, Li P-H, Hu D, Kuang G, Cao J, et al. Synthesis and evaluation of new quinoline derivatives for inhibition of hnRNP K in regulating oncogene c-myc transcription. Bioorganic Chem. 2019;85:1-17.

316. Deng J, Chen S, Wang F, Zhao H, Xie Z, Xu Z, et al. Effects of hnRNP A2/B1 knockdown on inhibition of glioblastoma cell invasion, growth and survival. Mol Neurobiol. 2016;53:1132-44.

317. Pu D, Li W-M, Zhou T-Y, Wu D, Chen X-B, Chen M, et al. The inhibitory effect of siRNA expression vector on cell proliferation and expression of nhRNPB1 gene in lung cancer A459 cells. Sichuan Da Xue Xue Bao Yi Xue Ban. 2009:40:389-92.

318. Verma N, Kaur G. In-silico designing of hnRNP B1 inhibitors against lung cancer: a computational approach. J Biomed Engineering Informatics. 2016; 2:47-56.

319. Zhou X, Li Q, He J, Zhong L, Shu F, Xing R, Lv D, et al. HnRNP-L promotes prostate cancer progression by enhancing cell cycling and inhibiting apoptosis. Oncotarget. 2017;8:19342-53.

320. Suk FM, Lin SY, Lin RJ, Hsine YH, Liao YJ, Fang SU, et al. Bortezomib inhibits Burkitt's lymphoma cell proliferation by downregulating sumoylated hnRNP $\mathrm{K}$ and c-Myc expression. Oncotarget. 2015;6:25988-6001.

321. Yang H, Zhu R, Xhao X, Liu L, Zhou Z, Zhao L, Liang B, et al. Sirtuinmediated deacetylation of hnRNP A1 suppresses glycolysis and growth in hepatocellular carcinoma. Oncogene. 2019;38:4915-31.

322. ElHady AK, Abdel Halim M, Abadi A, Engel M. Development of selective Clk and -4 inhibitors for cellular depletion of cancer relevant proteins. J Med Chem. 2017;60:5377-91.

323. Lee JY, Yun JS, Kim WK, Chun HS, Jin H, Cho S, et al. Structural basis for the selective inhibition of cdc2-like kinases by CXC-4945. Biomed Res Int. 2019; 2019:6125068. https://doi.org/10.1155/2019/6125068.

324. Tam BY, Chiu K, Chung H, Bossard C, Nguyen JD, Creger E, et al. The CLK inhibitor SM08502 induces anti-tumor activity and reduces Wnt pathway gene expression in gastrointestinal cancer models. Cancer Letters. 2020;473: 186-97.

325. Chang J-G, Yang DM, Chang WH, Choe LP, Chan WL, Lin HH, et al. Small molecule amiloride modulates oncogenic RNA alternative splicing to devitilize human cancer cells. PLOS ONE. 2011;6:e18643.

326. Lu R-M, Hwang YC, IJu L, Lee CC, Tsai HZ, Li HJ, et al. Development of therapeutic antibodies for treatment of diseases. J Biomed Sci. 2020;27:1 https://doi.org/10.1186/s12929-019-0592-z.

327. An Z, Aksoy O, Zheng T, Fan QW, Weiss WA. Epidermal growth factor receptor and EGFRVIII in glioblastoma: signaling pathways and targeted therapies. Oncogene. 2018;37:1561-75.

328. Lang AM, Lo H-W. Inhibiting Trk proteins in clinical cancer therapy. Cancers. 2018;10. https://doi.org/10.3390/cancers10040105.

329. Yoa H-P, Feng L, Suthe SR, Chen L-H, Weng T-H, Hu C-Y, et al. Therapeutic efficacy, pharmacokinetic profiles, and toxicological activities of humanized antibody-drug conjugate Zt/g4-MMAE targeting RON receptor tyrosine kinase for cancer therapy. J Immunother Cancer. 2019;7:75. https://doi.org/ 10.1186/s40425-019-0525-0.

330. Schumacher K. Keyhole limpet hemocyanin (KLH) conjugate vaccines as novel therapeutic tools in malignant disorders. J Cancer Res Clin Oncol. 2001;127(Suppl 2):R1-2

331. Martinez M, Moon EK. CAR T cells for solid tumors: New strategies for finding, infiltrating, and surviving in the tumor microenvironment. Front Immunol. 2019;10:12. https://doi.org/10.3389/fimmu.2019.00128.

\section{Publisher's Note}

Springer Nature remains neutral with regard to jurisdictional claims in published maps and institutional affiliations.

Ready to submit your research? Choose BMC and benefit from:

- fast, convenient online submission

- thorough peer review by experienced researchers in your field

- rapid publication on acceptance

- support for research data, including large and complex data types

- gold Open Access which fosters wider collaboration and increased citations

- maximum visibility for your research: over $100 \mathrm{M}$ website views per year

At $\mathrm{BMC}$, research is always in progress.

Learn more biomedcentral.com/submissions 